\title{
Measurement of the partial photoionization cross sections and asymmetry parameters of $S$ atoms in the photon energy range 10.0-30.0 eV using constant-ionic-state spectroscopy
}

\author{
Fabrizio Innocenti and Lucia Zuin \\ Department of Chemistry, University of Southampton, Highfield, Southampton SO17 1BJ, United Kingdom \\ Maria L. Costa and Antonio A. Dias \\ CEFITEC, Department of Physics, Faculdade de Ciencias e Tecnologia, Universidade Nova de Lisboa, \\ 2829-516 Caparica, Portugal \\ Alan Morris \\ Department of Chemistry, University of Southampton, Highfield, Southampton SO17 1BJ, United Kingdom \\ Stefano Stranges \\ Department of Chemistry, ISMN-CNR Sezione Roma La Sapienza I-00185, Italy and INSTM, Unita di \\ Roma, La Sapienza, Italy \\ John M. Dyke ${ }^{a)}$ \\ Department of Chemistry, University of Southampton, Highfield, Southampton SO17 1BJ, United Kingdom
}

(Received 17 January 2007; accepted 5 March 2007; published online 17 April 2007)

\begin{abstract}
The partial photoionization cross sections and asymmetry parameters of $\mathrm{S}$ atoms have been measured using constant-ionic-state (CIS) spectroscopy in the photon energy range 10.0-30.0 eV. The ionizations investigated in these CIS experiments are the $(3 p)^{-1}$ ionizations $\mathrm{S}^{+}\left({ }^{4} S\right) \leftarrow \mathrm{S}\left({ }^{3} P\right)$, $\mathrm{S}^{+}\left({ }^{2} D\right) \leftarrow \mathrm{S}\left({ }^{3} P\right)$, and $\mathrm{S}^{+}\left({ }^{2} P\right) \leftarrow \mathrm{S}\left({ }^{3} P\right)$. For the first time Rydberg series which converge to the fourth ionization limit have been observed and assignments of these series have been proposed. These correspond to excitations to Rydberg states that are parts of series which converge to the fourth ionization limit, $\mathrm{S}^{+}\left({ }^{4} P\right) \leftarrow \mathrm{S}\left({ }^{3} P\right)(3 s)^{-1}$, and autoionize to the lower $\mathrm{S}^{+}\left({ }^{4} S\right), \mathrm{S}^{+}\left({ }^{2} D\right)$, or $\mathrm{S}^{+}\left({ }^{2} P\right)$ states. For each series observed in the CIS spectra photoelectron angular distribution studies, combined with other evidence, has allowed the angular momentum character of the free electron on autoionization to be determined. (C) 2007 American Institute of Physics. [DOI: 10.1063/1.2720391]
\end{abstract}

\section{INTRODUCTION}

In this paper, we report measurements of the partial photoionization cross sections and photoelectron asymmetry parameters $(\beta)$ of sulfur atoms in the photon energy range $10.0-30.0 \mathrm{eV}$, using constant-ionic-state (CIS) spectroscopy. This study builds on and extends an initial investigation of $S$ and SH that we performed with photoelectron spectroscopy (PES) in which PE spectra were recorded at different photon energies in the region $9.6-15.2 \mathrm{eV} .^{1}$ This is part of an ongoing research project to study the photoionization behavior of reactive atoms and molecules with synchrotron radiation. ${ }^{2-6}$

This work on $\mathrm{S}$ atoms is both of fundamental importance and relevant to the properties of the solar atmosphere. The fundamental interest in $\mathrm{S}$ atoms arises from a need to understand the photoionization behavior of reactive open shell atoms, ${ }^{7}$ a topic that we have already contributed to with angularly resolved PES and CIS studies on $\mathrm{O}$ and $\mathrm{N}$ atoms with synchrotron radiation. ${ }^{2,3}$ Also, the interaction of $\mathrm{S}$ atoms with ultraviolet and vacuum ultraviolet radiation is important in the solar atmosphere ${ }^{8}$ and, due to its relatively high solar abundance, ${ }^{9}$ sulfur plays an important role in determining solar and stellar opacities. ${ }^{10,11}$

\footnotetext{
${ }^{a)}$ Author to whom correspondence should be addressed.
}

The ground state electronic configuration of $\mathrm{S}$ atoms is $1 s^{2} 2 s^{2} 2 p^{6} 3 s^{2} 3 p^{4}{ }^{3} P$. Three ionic states arise from $(3 p)^{-1}$ ionization from this state, which are allowed by the one-electron selection rule, the ${ }^{4} S,{ }^{2} D$, and ${ }^{2} P$ states at ionization energies (IEs) of $10.35,12.20$, and $13.40 \mathrm{eV}$, respectively. ${ }^{12}$ Two ionic states arise from the $(3 s)^{-1}$ ionization, which are allowed by the one-electron selection rule, the ${ }^{4} P$ and ${ }^{2} P$ states, at ionization energies of 20.20 and $23.45 \mathrm{eV}^{12}$

A number of experimental and theoretical studies have been made on $\mathrm{S}$ atoms and these have been summarized in our earlier study. ${ }^{1}$ Of the previous experimental work, the most relevant to this present paper is the investigation of Gibson et al. ${ }^{13}$ who studied the photoionization spectrum of atomic sulfur using photoionization mass spectrometry from the ionization threshold, $10.35 \mathrm{eV}$, to $13.40 \mathrm{eV}$, and the work of Tondello, ${ }^{14}$ who measured and analyzed the absorption spectrum of S from 6.77 to $13.77 \mathrm{eV}$. Also, Woutersen et al. ${ }^{15,16}$ investigated sulfur atoms with $(2+1)$ resonanceenhanced multiphoton ionization spectroscopy and observed even-parity Rydberg states, allowed by two-photon excitation from the ground state, with $\mathrm{S}^{+2} D$ and ${ }^{2} P$ ionic cores above the lowest ionization threshold. The most relevant theoretical work is that of Dill et al., ${ }^{17}$ who obtained photoelectron $\beta$ parameters for the $(3 p)^{-1} \mathrm{~S}^{+}\left({ }^{4} S,{ }^{2} D,{ }^{2} P\right) \leftarrow \mathrm{S}\left({ }^{3} P\right)$ ionizations in the photon energy region $10.0-65.0 \mathrm{eV}$ using 
Hartree-Fock calculations with explicit expressions for the angular distribution of photoelectrons produced by electric dipole ionization of closed and open shell atoms.

In our first study on $\mathrm{S}$ atoms with synchrotron radiation, ${ }^{1}$ PE spectra were recorded of the first three bands of $\mathrm{S}$ atoms, corresponding to the $(3 p)^{-1} \mathrm{~S}^{+}\left({ }^{4} S,{ }^{2} D,{ }^{2} P\right) \leftarrow \mathrm{S}\left({ }^{3} P\right)$ ionizations at photon energies in the region $9.600-18.494 \mathrm{eV}$ at two different angles $\left(0^{\circ}\right.$ and $\left.54^{\circ} 44^{\prime}\right)$ with respect to the direction of linear polarization of the photon beam. Different photon energy step sizes were used for different parts of this energy range, with the smallest step size $(0.20 \mathrm{eV})$ being used in the photon energy range $13.205-16.420 \mathrm{eV} .{ }^{1}$ In this present work, the higher resolution CIS method has been used to study the $\mathrm{S}^{+}\left({ }^{4} S,{ }^{2} D,{ }^{2} P\right) \leftarrow \mathrm{S}\left({ }^{3} P\right)(3 p)^{-1} \mathrm{PE}$ bands in the photon energy range $10.0-30.0 \mathrm{eV}$ using a $1 \mathrm{meV}$ step size at two angles $\left(0^{\circ}\right.$ and $\left.54^{\circ} 44^{\prime}\right)$ with respect to the direction of linear polarization of the photon beam.

This work therefore extends the earlier work by measuring partial photoionization cross sections and asymmetry parameters for the $\mathrm{S}^{+}\left({ }^{4} S,{ }^{2} D,{ }^{2} P\right) \leftarrow \mathrm{S}\left({ }^{3} P\right)(3 p)^{-1}$ ionizations by using (i) a wider photon energy range and (ii) a higher resolution method (CIS) with a much smaller step size than used in Ref. 1.

\section{EXPERIMENT}

The experiments were carried out using the same spectrometer as described in Ref. 1 at the circularly polarized beamline (4.2R) at the Elettra Synchrotron Light Source (Trieste).

PE spectra were recorded in the constant pass energy mode, by scanning the voltage on a lens which accelerates (or decelerates) the photoelectrons before they enter the analyzer, as described in the earlier work. ${ }^{1}$

$\mathrm{S}$ atoms were produced by the following consecutive rapid reactions:

$$
\begin{aligned}
& \mathrm{F}+\mathrm{H}_{2} \mathrm{~S} \rightarrow \mathrm{SH}+\mathrm{HF}, \\
& \mathrm{F}+\mathrm{SH} \rightarrow \mathrm{S}+\mathrm{HF} .
\end{aligned}
$$

To obtain a high F-atom yield, fluorine atoms were produced by flowing $5 \% \mathrm{~F}_{2}$ in helium through a microwave discharge at $2.45 \mathrm{GHz}$ in the sidearm of a glass inlet system, ${ }^{18}$ with an inner inlet system which is the inlet used for the target molecules (in this case $\mathrm{H}_{2} \mathrm{~S}$ ). The intensities of the bands in the experimental PE and CIS spectra were normalized by the photon flux and then by the transmission correction of the spectrometer, as explained in Ref. 1. The degree of linear polarization $(P=1)$ of the radiation is well established. ${ }^{19,20}$ The photoelectron asymmetry parameter $(\beta)$ was measured for $\mathrm{S}$ at selected photon energies and over a photon energy range by recording CIS spectra at two different angles $\left(\theta=0^{\circ}\right.$ and $\left.54^{\circ} 44^{\prime}\right)$ at each photon energy (at $54^{\circ} 44^{\prime}$ the measured intensity is proportional to the total photoionization cross section, independent of $\beta$ ); the $\beta$ parameter was then calculated from

$$
\beta=(R-1),
$$

where $R=I_{0} / I_{54^{\circ}} 4_{4}$, is the ratio of the experimental intensities at these two angles, after applying the above corrections.

The photon energy was calibrated in the $11.5-29.0 \mathrm{eV}$ region against the energies of the $\operatorname{Ar} 3 s 3 p^{6}\left({ }^{2} S_{1 / 2}\right) n p$ $\leftarrow 3 s^{2} 3 p^{6}\left({ }^{1} S_{0}\right)$ resonances ${ }^{21}$ and He $1 s^{1} n p \leftarrow 1 s^{2}$ absorption lines. ${ }^{22}$ The Ar resonances were obtained by recording CIS spectra of the first band (first component) of the $(3 p)^{-1}$ ionization of argon in the photon energy region $26.0-29.0 \mathrm{eV}$. Absorption spectra of He were recorded by measuring the current on an aluminum plate at the side of the ionization chamber of the spectrometer opposite the photon source in the photon energy range $21.0-24.0 \mathrm{eV}$ using first order radiation and 11.5-12.3 eV using second order radiation.

Test experiments were carried out in Southampton in order to determine the optimum pressures and mixing distance above the photon beam to be used in the experiments at Elettra which maximize the intensities of the second and third photoelectron bands of $\mathrm{S}$ at 12.20 and $13.40 \mathrm{eV}$ IEs, respectively, corresponding to the ionizations $\mathrm{S}^{+}\left({ }^{2} D\right)$ $\leftarrow \mathrm{S}\left({ }^{3} P\right)$ and $\mathrm{S}^{+}\left({ }^{2} P\right) \leftarrow \mathrm{S}\left({ }^{3} P\right) .{ }^{23}$ The following conditions were found to be the optimum for production of both $S$ and SH: a mixing distance above the photon beam of $2 \mathrm{~cm}$, with the inner-inlet system used for $\mathrm{H}_{2} \mathrm{~S}$ longer than the outer inlet system by about $2 \mathrm{~mm}$, and the partial pressures measured on an ionization gauge positioned on the wall of the ionization chamber of $\Delta p\left(\mathrm{H}_{2} \mathrm{~S}\right)=2.4 \times 10^{-7} \mathrm{mbar}$ and $\Delta p\left(\mathrm{~F}_{2} / \mathrm{He}\right)=4.6 \times 10^{-6} \mathrm{mbar}$.

In this investigation, better experimental conditions than in Ref. 1 allowed studies to be performed on S atoms over a wider photon energy range. This was because new software was written to allow PE and CIS spectra to be acquired and the experimental photoelectron resolution was better, which allowed the first PE bands of S and $\mathrm{SH}$ to be resolved.

\section{RESULTS AND DISCUSSION}

In Fig. 1, PE spectra recorded at Elettra of the products of the $\mathrm{F}+\mathrm{H}_{2} \mathrm{~S}$ reaction at a photon energy of $h \nu=21.26 \mathrm{eV}$ and at two different angles with respect to the polarization axis of the photon source $\left(\theta=0^{\circ}\right.$ and $\left.\theta=54^{\circ} 44^{\prime}\right)$ are shown with the assignment of the major features indicated. These spectra show sharp bands at 11.64 and $12.76 \mathrm{eV}$, which are the second and third bands of $\mathrm{SH}$, and sharp bands at 12.20 and $13.40 \mathrm{eV}$, which are the second and third bands of $\mathrm{S}$ atoms. Also the first bands of $\mathrm{O}$ atoms $(13.62 \mathrm{eV})$ (Ref. 12) and $\mathrm{H}_{2} \mathrm{O}(12.62 \mathrm{eV})$ (Ref. 24) are observed. $\mathrm{H}_{2} \mathrm{O}$ arises from residual water in the inlet system and $\mathrm{O}$ atoms probably arise from reaction of $\mathrm{F}$ atoms with $\mathrm{H}_{2} \mathrm{O}$. Compared with Fig. 2 of Ref. 1, the first band of $\mathrm{S}$ atoms at $10.35 \mathrm{eV}$ is resolved from the first band of $\mathrm{SH}$ at $10.42 \mathrm{eV}$ and the small contribution from the first band of residual $\mathrm{H}_{2} \mathrm{~S}$ at $10.48 \mathrm{eV} .^{24}$ The vibrationally resolved band at $14.11 \mathrm{eV}$ adiabatic ionization energy is the fourth band of $\mathrm{SH}$, the $\mathrm{SH}^{+}\left(A^{3} \Pi\right) \leftarrow \mathrm{SH}\left(X^{2} \Pi\right)$ ionization.

CIS spectra were recorded for the $\mathrm{S}^{+}\left({ }^{4} S\right) \leftarrow \mathrm{S}\left({ }^{3} P\right)$ ionization at $10.35 \mathrm{eV}$, for the $\mathrm{S}^{+}\left({ }^{2} D\right) \leftarrow \mathrm{S}\left({ }^{3} P\right)$ ionization at $12.20 \mathrm{eV}$, and for the $\mathrm{S}^{+}\left({ }^{2} P\right) \leftarrow \mathrm{S}\left({ }^{3} P\right)$ ionization at $13.40 \mathrm{eV}$. All spectra were recorded at two angles, $\theta=0^{\circ}$ and $\theta$ 


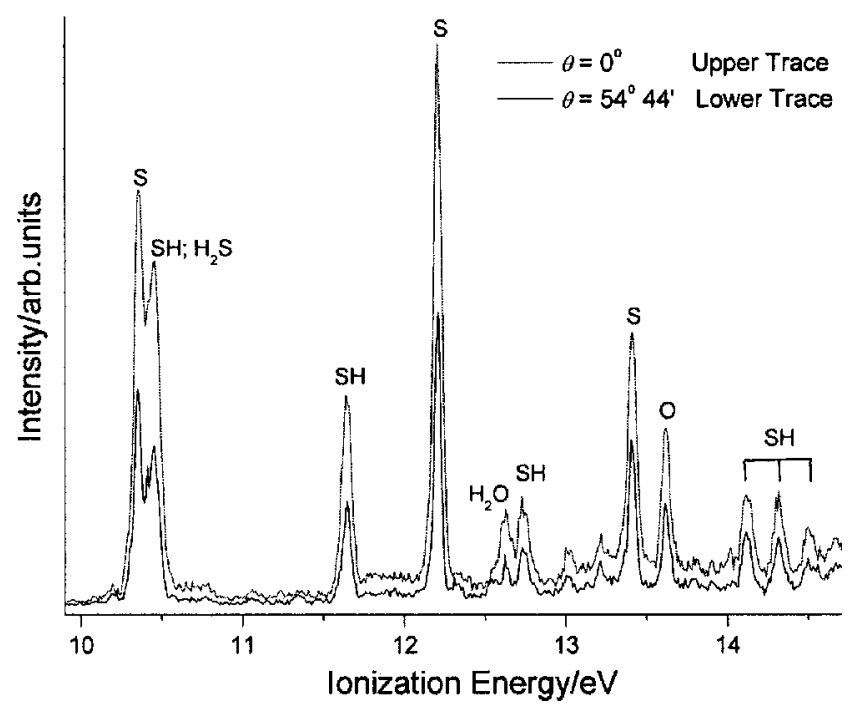

FIG. 1. Photoelectron spectrum at $h \nu=21.264 \mathrm{eV}$ of the consecutive reactions $\mathrm{F}+\mathrm{H}_{2} \mathrm{~S} \rightarrow \mathrm{SH}+\mathrm{HF}$ and $\mathrm{F}+\mathrm{HS} \rightarrow \mathrm{S}+\mathrm{HF}$ measured at two different angles $\theta=0^{\circ}$ (upper trace) and $\theta=54^{\circ} 44^{\prime}$ (lower trace) with respect to the major polarization axis of the photon source in the $10.0-15.0 \mathrm{eV}$ ionization region.

$=54^{\circ} 44^{\prime}$, with respect to the polarization axis of the photon source, with a $1 \mathrm{meV} / \mathrm{channel}$ step width. Figure 2 shows the $\mathrm{S}^{+}\left({ }^{4} S\right) \leftarrow \mathrm{S}\left({ }^{3} P\right)$ CIS spectrum in the photon energy region $11.5-30.0 \mathrm{eV}$, Fig. 3 shows the $\mathrm{S}^{+}\left({ }^{2} D\right) \leftarrow \mathrm{S}\left({ }^{3} P\right)$ CIS spectrum in the photon energy region $13.5-20.5 \mathrm{eV}$, and Fig. 4 shows the $\mathrm{S}^{+}\left({ }^{2} P\right) \leftarrow \mathrm{S}\left({ }^{3} P\right)$ CIS spectrum in the photon energy region $14.5-30.5 \mathrm{eV}$. These spectra were recorded at $\theta=54^{\circ} 44^{\prime}$.

The relative cross sections off resonance for the atomic sulfur CIS bands were estimated at a photon energy of $14.76 \mathrm{eV}$, an energy at which the total photoionization cross section has been obtained by extrapolation of Tondello's absolute measurements ${ }^{14}$ as $75 \mathrm{Mb}$, based on the linewidths of the absorption lines and the absorption oscillator strength measured in emission by Muller. ${ }^{25}$ In order to estimate the absolute cross section for these ionizations at $14.76 \mathrm{eV}$, the sum of the relative cross sections of these bands was normalized to the total cross section of $75 \mathrm{Mb}$, determined from Tondello's ${ }^{14}$ work. Once this had been done, the experimental results could be used to estimate the photoionization cross section for the first three bands of $\mathrm{S}$ atoms at $16.7 \mathrm{eV}$ (a photon energy at which the photoionization cross section has been calculated ${ }^{26}$ ), which when summed gave a total photoionization cross section of $68.7 \mathrm{Mb}$; this can be compared with the total photoionization cross section calculated by Yeh and Lindau ${ }^{26}$ as $18.2 \mathrm{Mb}$, using Hartree-Fock-Slater calculations. Bearing in mind that values of absolute cross sections can be obtained only if all the parameters are measured in the same experiment under the same experimental conditions, values of absolute cross sections using data extrapolations from other work, both experimental and theoretical, can be used only as a relative indication. Therefore, given the approximations involved, most notably that the total photoionization cross section in the present work has been referenced to the extrapolated photoionization cross section at $14.76 \mathrm{eV}$ determined by Tondello's measurements ${ }^{14}$ and that the over-
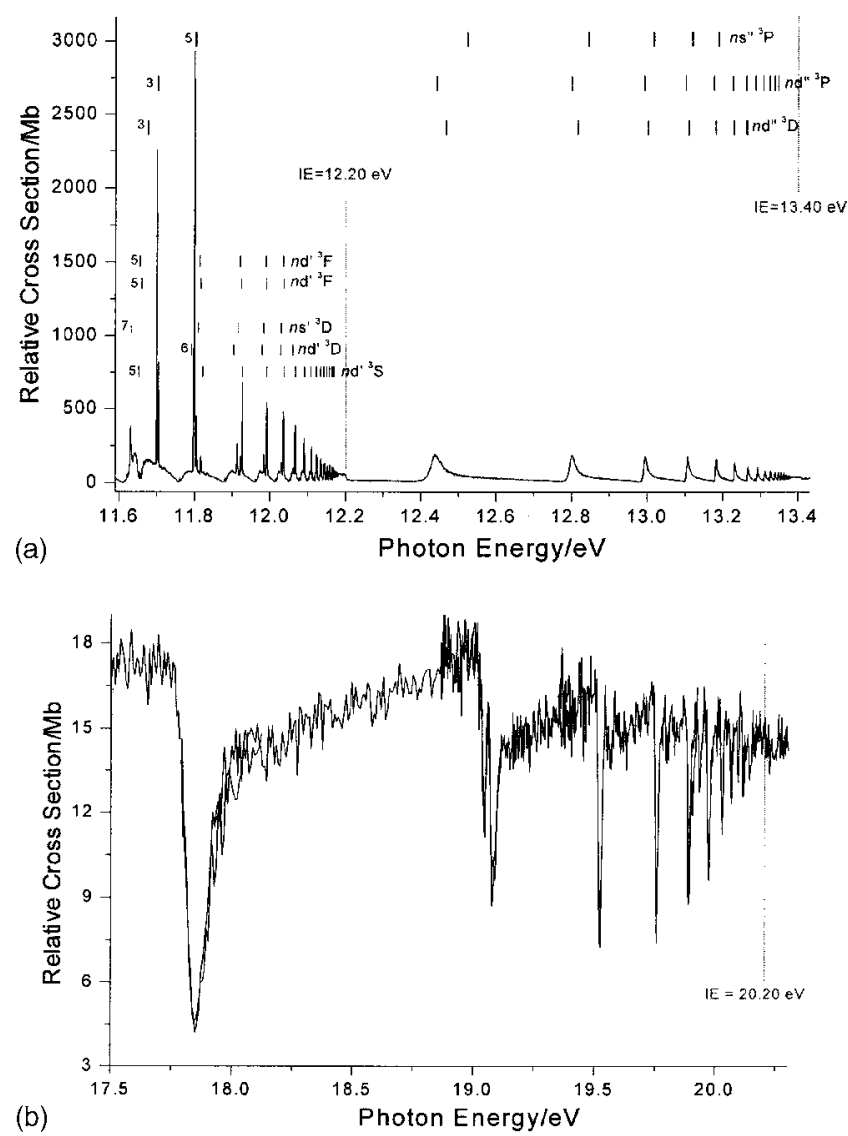

FIG. 2. (a) CIS spectrum recorded for the $\mathrm{S}^{+}\left({ }^{4} S\right) \leftarrow \mathrm{S}^{*} \leftarrow \mathrm{S}\left({ }^{3} P\right)$ process in the $11.60-13.45 \mathrm{eV}$ photon energy region at $\theta=54^{\circ} 44^{\prime}$ detection angle, with the second and third ionization limits marked. $S^{*} \leftarrow S$ transitions are indicated as in Refs. 13 and 27; single and double primes on the Rydberg electron in the excited state denote terms converging to the second (IE $=12.20 \mathrm{eV})$ and to the third $(\mathrm{IE}=13.40 \mathrm{eV})$ ionization limit, respectively. (b) CIS spectrum recorded for the $\mathrm{S}^{+}\left({ }^{4} S\right) \leftarrow \mathrm{S}^{*} \leftarrow \mathrm{S}\left({ }^{3} P\right)$ process in the $17.50-20.55 \mathrm{eV}$ photon energy region, at $\theta=54^{\circ} 44^{\prime}$ detection angle, with the fourth ionization limit marked.

all uncertainty in the cross sections determined by Tondello is estimated in Ref. 14 to be $50 \%$, as well as the approximate nature of the calculations of Ref. 26, it is not surprising that poor agreement is obtained with the computed value of Yeh and Lindau. ${ }^{26}$ Nevertheless, this comparison indicates that there is a clear need for a direct measurement of the absolute photoionization cross section of atomic sulfur in the vacuum ultraviolet region. The results of the above normalization obtained from Tondello results ${ }^{14}$ have been applied in Figs. $2-4$. This normalization has been preferred over the one carried out in the earlier work, ${ }^{1}$ which used the value by Yeh and Lindau ${ }^{26}$ from Hartree-Fock-Slater calculations, because it is obtained from experimental measurements.

\section{A. $S^{+}\left({ }^{4} S\right) \leftarrow S^{*} \leftarrow S\left({ }^{3} P\right)$ and $S^{+}\left({ }^{2} D\right) \leftarrow S^{*} \leftarrow S\left({ }^{3} P\right)$ CIS spectra which show series which converge to the second and third ionization limits}

The $\mathrm{S}^{+}\left({ }^{4} S\right) \leftarrow \mathrm{S}^{*} \leftarrow \mathrm{S}\left({ }^{3} P\right)$ and $\mathrm{S}^{+}\left({ }^{2} D\right) \leftarrow \mathrm{S}^{*} \leftarrow \mathrm{S}\left({ }^{3} P\right)$ CIS spectra in the photon energy regions 11.60-13.45 and 13.10-13.42 eV, respectively, with the second and third ionization limits marked in are shown in Figs. 2(a) and 3(b), respectively, recorded at $\theta=54^{\circ} 44^{\prime}$. All of the $S^{*} \leftarrow S\left({ }^{3} P\right)$ 

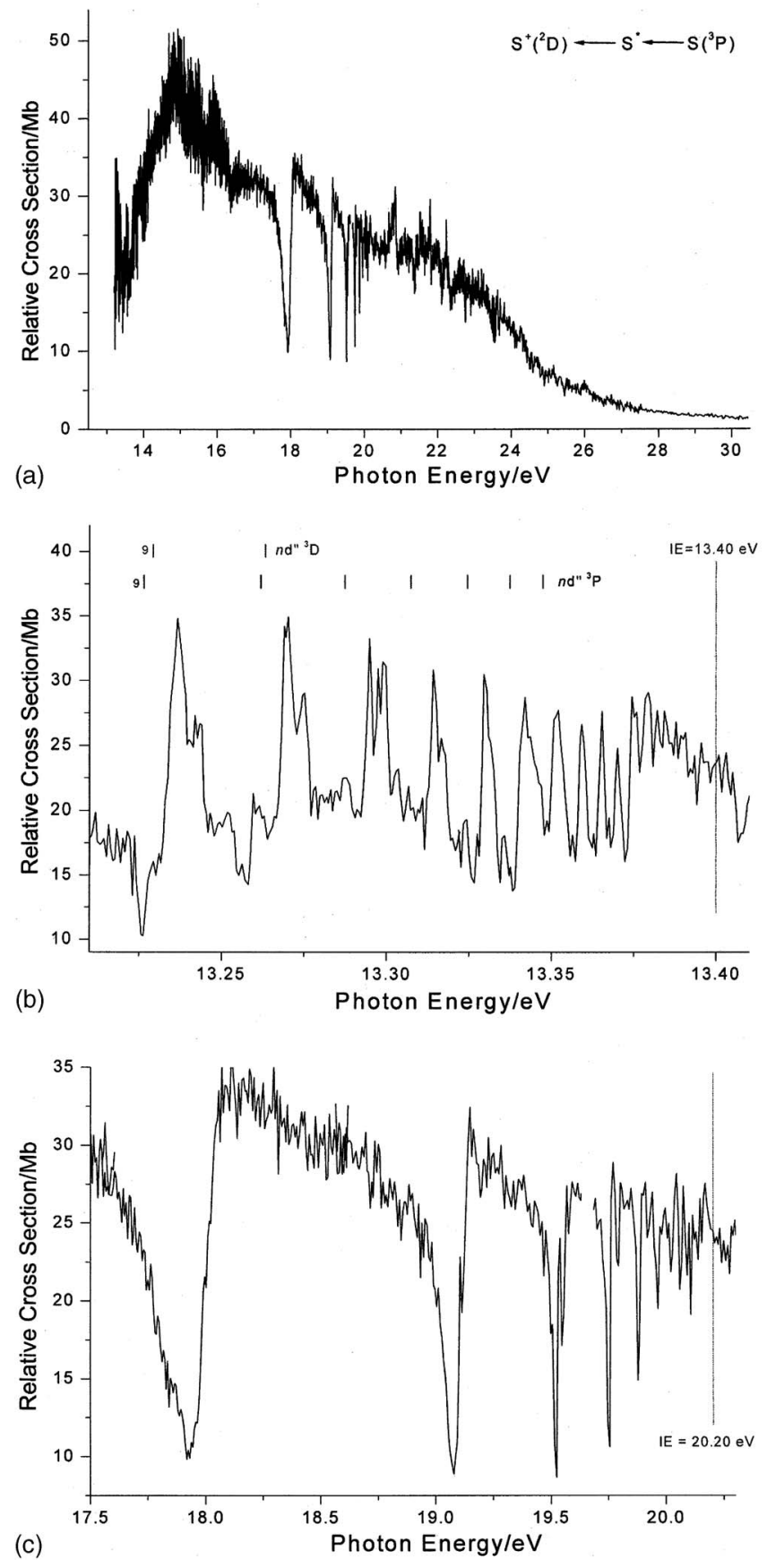

FIG. 3. (a) CIS spectrum recorded for the $\mathrm{S}^{+}\left({ }^{2} D\right) \leftarrow \mathrm{S}^{*} \leftarrow \mathrm{S}\left({ }^{3} P\right)$ process in the $13.5-30.5 \mathrm{eV}$ photon energy region at $\theta=54^{\circ} 44^{\prime}$ detection angle. (b) CIS spectrum recorded for the $\mathrm{S}^{+}\left({ }^{2} D\right) \leftarrow \mathrm{S}^{*} \leftarrow \mathrm{S}\left({ }^{3} P\right)$ process in the $13.10-13.42 \mathrm{eV}$ photon energy region at $\theta=54^{\circ} 44^{\prime}$ detection angle with the third ionization limits marked. $\mathrm{S}^{*} \leftarrow \mathrm{S}$ transitions are indicated as in Refs. 13 and 27; double prime on the Rydberg electron in the excited state denotes terms converging to the third ionization limit. (c) CIS spectrum recorded for the $\mathrm{S}^{+}\left({ }^{2} D\right) \leftarrow \mathrm{S}^{*} \leftarrow \mathrm{S}\left({ }^{3} P\right)$ process in the $17.5-20.3 \mathrm{eV}$ photon energy region at $\theta=54^{\circ} 44^{\prime}$ detection angle with the fourth ionization limit marked.

transitions observed have been seen previously, ${ }^{13,14,27}$ but this is their first observation by CIS spectroscopy. The bands observed in these figures can be readily assigned by comparison with known $\mathrm{S}^{*}$ term values. ${ }^{13,14,27}$ The energy positions of the resonances, taken as the band maxima, have been fitted using the Rydberg energy formula and good agreement has been found with the results of previous studies of the
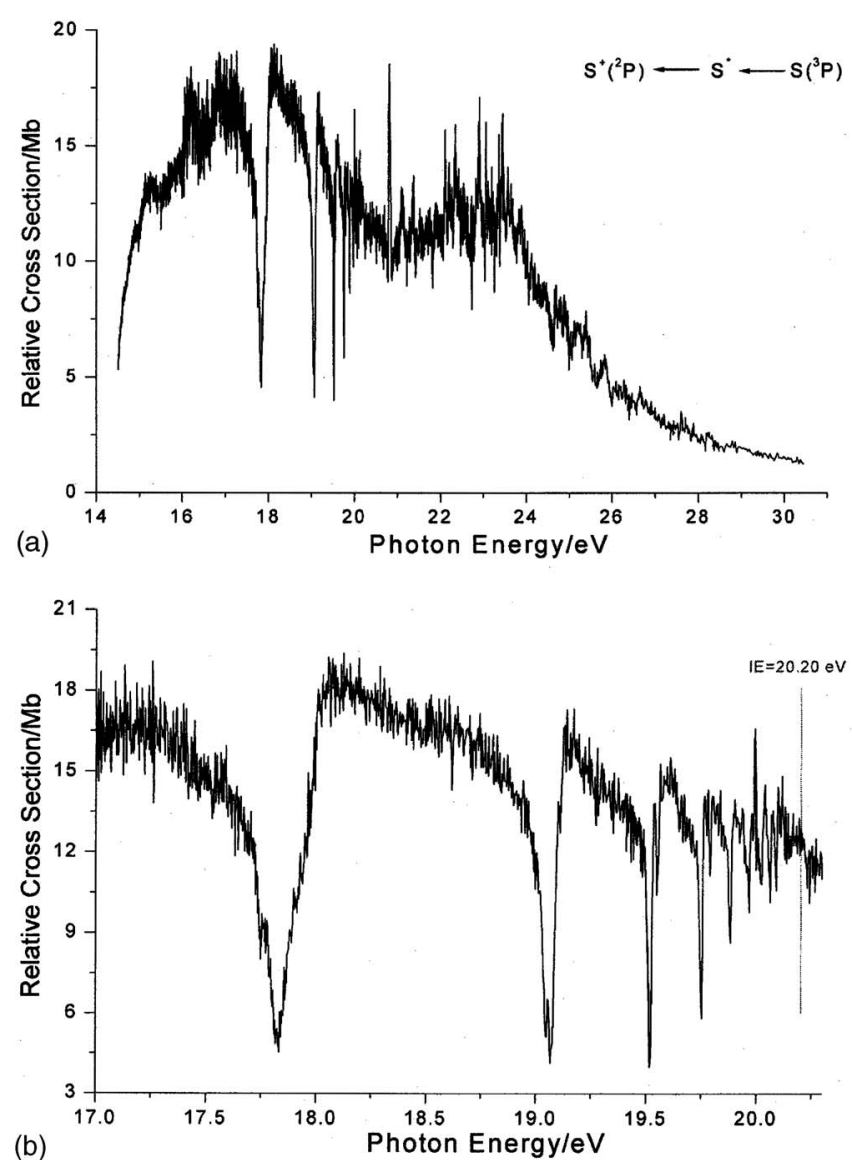

FIG. 4. (a) CIS spectrum recorded for the $\mathrm{S}^{+}\left({ }^{2} P\right) \leftarrow \mathrm{S}^{*} \leftarrow \mathrm{S}\left({ }^{3} P\right)$ process in the $14.5-30.5 \mathrm{eV}$ photon energy region at $\theta=54^{\circ} 44^{\prime}$ detection angle. (b) CIS spectrum recorded for the $\mathrm{S}^{+}\left({ }^{2} P\right) \leftarrow \mathrm{S}^{*} \leftarrow \mathrm{S}\left({ }^{3} P\right)$ process in the $17.0-20.3 \mathrm{eV}$ photon energy region at $\theta=54^{\circ} 44^{\prime}$ detection angle with the fourth ionization limit marked.

photoabsorption spectrum of Joshi et $a .^{27}$ and the photoionization mass-selected spectrum of Gibson et al. ${ }^{13}$ Examples of the results obtained for the $n=7 n s^{\prime}{ }^{3} D, n d^{\prime}{ }^{3} D$, and $n d^{\prime}{ }^{3} S$ Rydberg states by these fits have been summarized in Table I, where they are compared with the results obtained by Gibson et al. ${ }^{13}$ for the Rydberg series shown in Fig. 2(a). Inspection of the CIS spectrum recorded for the first PE band of $\mathrm{S}$ atoms shows that in the photon energy region 11.60-12.20 eV, all the bands can be assigned to excitation to Rydberg states which are members of series which converge to the second and to the third ionization energy, see Fig. 2(a). The structure observed in Fig. 2(a) in the region 12.20-13.40 eV and in Fig. 3(b) was investigated and assigned to the $\left[3 s^{2} 3 p^{3}\left({ }^{2} P\right) n s\right]{ }^{3} P,\left[3 s^{2} 3 p^{3}\left({ }^{2} P\right) n d\right]{ }^{3} P$, and $\left[3 s^{2} 3 p^{3}\left({ }^{2} P\right) n d\right]^{3} D$ Rydberg series accessed from the $3 s^{2} 3 p^{4}{ }^{3} P$ ground state. These Rydberg states are parts of series which converge to the third ionization limit at $13.400 \mathrm{eV} .^{13,27}$ The position and assignment of these states have been established previously by Joshi et al. ${ }^{27}$ and Gibson et al. ${ }^{13}$

Comparing Fig. 3(b), a CIS spectrum for $\mathrm{S}^{+}\left({ }^{2} D\right)$ $\leftarrow S\left({ }^{3} P\right)$ in the photon energy region $13.10-13.42 \mathrm{eV}$, with Fig. 6(b) of Ref. 1 obtained by PES, it can be seen that in the $\mathrm{PE}$ study ${ }^{1}$ structure is observed in the $13.2-13.3 \mathrm{eV}$ region which is reproduced in the CIS scan; this extends into the 
TABLE I. Examples of results obtained for $n=7 \mathrm{~ns}{ }^{3} D, n d^{3} D$, and $n d^{3} S$ Rydberg states, which are parts of Rydberg series converging to the second ionization limit listing the fitted quantum defects and fitted ionization limits obtained in this work compared with the results of Ref. 13 [see Fig. 2(a)].

\begin{tabular}{ccccccc}
\hline \hline & & \multicolumn{2}{c}{ Present work } & & \multicolumn{2}{c}{ Results of Ref. 13 } \\
\cline { 3 - 4 } $\begin{array}{c}\text { Excitation } \\
\text { energy (eV) }\end{array}$ & $\begin{array}{c}\text { Rydberg } \\
\text { series }\end{array}$ & $\begin{array}{c}\text { Quantum } \\
\text { defect } \delta\end{array}$ & $\begin{array}{c}\text { Ionization } \\
\text { limit IE (eV) }\end{array}$ & & $\begin{array}{c}\text { Quantum } \\
\text { defect } \delta\end{array}$ & $\begin{array}{c}\text { Ionization } \\
\text { limit IE (eV) }\end{array}$ \\
\hline 11.907 & $n d^{\prime}{ }^{3} D$ & 0.31 & 12.20 & & 0.27 & 12.20 \\
11.633 & $n s^{\prime}{ }^{3} D$ & 2.13 & 12.20 & & 2.12 & 12.20 \\
11.929 & $n d^{\prime 3} S$ & 0.04 & 12.20 & & -0.03 & 12.20 \\
\hline
\end{tabular}

${ }^{\mathrm{a}}$ The weighted average of the ${ }^{2} D_{3 / 2}$ and ${ }^{2} D_{5 / 2}$ limits has been used in Ref. 13 to calculate the quantum defects. See Fig. 2(a) for the other Rydberg states which are parts of series converging to the second and third ionization energy limits. The CIS spectra in this figure were recorded in the $11.6-13.4 \mathrm{eV}$ region.

energy region $13.3-13.4 \mathrm{eV}$ in the CIS scan of Fig. 3(b). The resonances in the $13.3-13.4 \mathrm{eV}$ region could easily be misinterpreted in the PES study as background due to the low count rate and large step width used while the CIS study confirms the presence of real structure which is part of a series converging to the third ionization limit.

Also, the structure observed in Fig. 7(c) of Ref. 1 of the relative cross section for the $\mathrm{S}^{+}\left({ }^{2} P\right) \leftarrow \mathrm{S}\left({ }^{3} P\right)$ ionization in the $14.00-16.00 \mathrm{eV}$ photon energy region has been investigated again to see if the small maxima observed (at 14.96 and $15.37 \mathrm{eV})$ are really parts of excitation to $\left[3 s^{1} 3 p^{4}\left({ }^{4} P\right) n p\right]^{3} D /{ }^{3} P /{ }^{3} S$ or $\left[3 s^{1} 3 p^{4}\left({ }^{2} D\right) n p\right]^{3} D /{ }^{3} P /{ }^{3} S$ states accessed from the $3 s^{2} 3 p^{4}\left({ }^{3} P\right)$ state as proposed in the PE study. In Fig. 4(a), where the $\mathrm{S}^{+}\left({ }^{2} P\right) \leftarrow \mathrm{S}\left({ }^{3} P\right)$ CIS spectrum in the photon energy region $14.5-30.5 \mathrm{eV}$ is presented, no evidence of structure was observed in these positions. Also, no maxima were seen in CIS scans of the first and second bands at these photon energies. In this region the cross section for the $\mathrm{S}^{+}\left({ }^{2} P\right) \leftarrow \mathrm{S}\left({ }^{3} P\right)$ ionization is increasing with increasing photon energy and it appears that incorrect maxima were inferred from the earlier PE study because the data points were taken with a much larger step width than used in the present work.

\section{B. $S^{+}\left({ }^{4} S\right) \leftarrow S^{*} \leftarrow S\left({ }^{3} P\right), S^{+}\left({ }^{2} D\right) \leftarrow S^{*} \leftarrow S\left({ }^{3} P\right)$, and $S^{+}\left({ }^{2} P\right)$ $\leftarrow S^{*} \leftarrow S\left({ }^{3} P\right)$ CIS spectra which show series which converge to the fourth ionization limit}

Removal of a $3 s$ electron from the ground state of atomic sulfur gives rise to $3 s^{1} 3 p^{4}\left({ }^{4} P\right)$ and $3 s^{1} 3 p^{4}\left({ }^{2} P\right)$ ionic states at ionization energies of 20.201 and $23.449 \mathrm{eV}$, respectively. ${ }^{12} \quad$ The $\mathrm{S}^{+}\left({ }^{4} S\right) \leftarrow \mathrm{S}^{*} \leftarrow \mathrm{S}\left({ }^{3} P\right), \quad \mathrm{S}^{+}\left({ }^{2} D\right) \leftarrow \mathrm{S}^{*}$ $\leftarrow \mathrm{S}\left({ }^{3} P\right)$, and $\mathrm{S}^{+}\left({ }^{2} P\right) \leftarrow \mathrm{S}^{*} \leftarrow \mathrm{S}\left({ }^{3} P\right)$ CIS spectra up to $20.5 \mathrm{eV}$ are shown in Figs. 2(b), 3(c), and 4(b), respectively, and all are structured consisting of bands which are parts of series converging to the $\mathrm{S}^{+}\left({ }^{4} P\right) 3 s^{1} 3 p^{4} \leftarrow \mathrm{S}\left({ }^{3} P\right) 3 s^{2} 3 p^{4}$ limit.

In order to assign the bands in these figures, it is helpful to determine the term symbols of Rydberg states, which have a $3 s^{1} 3 p^{4}{ }^{4} P$ core, to which transitions are allowed from the $3 s^{2} 3 p^{4}{ }^{3} P$ ground state, and which autoionize to the $3 s^{2} 3 p^{3}$ $\mathrm{S}^{+}$states ${ }^{4} S,{ }^{2} D$, and ${ }^{2} P$. These states must be triplet states, since the spin selection rule, $\Delta S=0$, should be obeyed for a light atom such as sulfur. Also, the most intense transitions will be those with $\Delta 1= \pm 1$, or $p \leftarrow s$ in this case. ${ }^{28}$ The excited states involved may be considered to be the result of adding a $p$ electron to the $\mathrm{S}^{+}$state $3 s^{1} 3 p^{4}{ }^{4} P$, as they are parts of Rydberg series converging to this limit. The selection rule $\Delta L=0, \pm 1$ from the ground state of sulfur reduces the allowed states to those given in Table II.

The ${ }^{4} P$ core state of $\mathrm{S}^{+}$is spin-orbit split into three states ${ }^{4} P_{5 / 2},{ }^{4} P_{3 / 2}$, and ${ }^{4} P_{1 / 2}$ at ionization energies from $\mathrm{S}\left({ }^{3} P\right)$ of 20.201, 20.245, and $20.271 \mathrm{eV}$, respectively. ${ }^{12}$ The ground state of $\mathrm{S},{ }^{3} \mathrm{P}$, is spin-orbit split into three states, ${ }^{3} P_{2,1,0}$. The energy differences between the ${ }^{3} P_{2}$ ground state and ${ }^{3} P_{1}$, and the ${ }^{3} P_{2}$ state and ${ }^{3} P_{0}$ are 49 and $71 \mathrm{meV}$, respectively. The ${ }^{3} P_{2}$ state will be the most populated at room temperature. Therefore from Table II it can be seen that in the $\mathrm{S}^{+}\left({ }^{2} D\right) \leftarrow \mathrm{S}^{*} \leftarrow \mathrm{S}\left({ }^{3} P\right)$ CIS spectra, ignoring contributions from the $S\left({ }^{3} P_{1}\right)$ and $S\left({ }^{3} P_{0}\right)$ states, it should be possible to observe nine series for the $\mathrm{S}^{+}\left({ }^{2} D\right) \leftarrow \mathrm{S}^{*} \leftarrow \mathrm{S}\left({ }^{3} P\right)$ process (i.e., three Rydberg series each converging to three ionic limits, see the middle three rows of Table II) and six series for the $\mathrm{S}^{+}\left({ }^{4} S\right) \leftarrow \mathrm{S}^{*} \leftarrow \mathrm{S}\left({ }^{3} P\right)$ and $\mathrm{S}^{+}\left({ }^{2} P\right) \leftarrow \mathrm{S}^{*} \leftarrow \mathrm{S}\left({ }^{3} P\right)$ processes (i.e., in each case two Rydberg series each converging to three ionic limits, see upper three and lower three rows in Table II).

Photoabsorption cross sections in regions of autoionization can be parametrized with a line shape formula based on multichannel quantum defect theory (MQDT) analogous to Fano's resonance formula. ${ }^{29-31}$ This approach was used to

TABLE II. States to which transitions are allowed from the ground state $3 s^{2} 3 p^{4}{ }^{3} P$ (see text for further details).

\begin{tabular}{ll}
\hline \hline Excited state & Ionic state after autoionization \\
\hline$\left[3 s 3 p^{4}\left({ }^{4} P\right) n p\right]{ }^{3} D$ & $\mathrm{~S}^{+}\left({ }^{4} S\right), \varepsilon d$ \\
{$\left[3 s 3 p^{4}\left({ }^{4} P\right) n p\right]{ }^{3} P$} & $(a)$ \\
$\left.\left[3 s 3 p^{4}\left({ }^{\mathrm{a}} P\right) n p\right]\right]^{3} S$ & $\mathrm{~S}^{+}\left({ }^{4} S\right), \varepsilon s$ \\
{$\left[3 s 3 p^{4}\left({ }^{4} P\right) n p\right]{ }^{3} D$} & $\mathrm{~S}^{+}\left({ }^{2} D\right), \varepsilon s ; \mathrm{S}^{+}\left({ }^{2} D\right), \varepsilon d$ \\
$\left.\left[3 s 3 p^{4}\left({ }^{4} P\right) n p\right]\right]^{3} P$ & $\mathrm{~S}^{+}\left({ }^{2} D\right), \varepsilon d$ \\
$\left.\left[3 s 3 p^{4}\left({ }^{4} P\right) n p\right]\right]^{3} S$ & $\mathrm{~S}^{+}\left({ }^{2} D\right), \varepsilon d$ \\
{$\left[3 s 3 p^{4}\left({ }^{4} P\right) n p\right]{ }^{3} D$} & $\mathrm{~S}^{+}\left({ }^{2} P\right), \varepsilon d$ \\
$\left.\left[3 s 3 p^{4}\left({ }^{4} P\right) n p\right]\right]^{3} P$ & $\mathrm{~S}^{+}\left({ }^{2} P\right), \varepsilon s ; \mathrm{S}^{+}\left({ }^{2} P\right), \varepsilon d$ \\
{$\left[3 s 3 p^{4}\left({ }^{4} P\right) n p\right]{ }^{3} S$} & $(a)^{\mathrm{a}}$ \\
\hline
\end{tabular}

${ }^{\text {a State (a) requires a final state configuration with an ionic core where } \varepsilon p \text { is }}$ the free electron, which is not allowed by parity rules for autoionization from the excited state considered. 
simulate the $\mathrm{S}^{+}\left({ }^{4} S\right) \leftarrow \mathrm{S}^{*} \leftarrow \mathrm{S}\left({ }^{3} P\right), \mathrm{S}^{+}\left({ }^{2} D\right) \leftarrow \mathrm{S}^{*} \leftarrow \mathrm{S}\left({ }^{3} P\right)$, and $\mathrm{S}^{+}\left({ }^{2} P\right) \leftarrow \mathrm{S}^{*} \leftarrow \mathrm{S}\left({ }^{3} P\right)$ CIS spectra recorded up to $20.2 \mathrm{eV}$, the $\mathrm{S}^{+}\left({ }^{4} P\right) \leftarrow \mathrm{S}\left({ }^{3} P\right)(4 s)^{-1}$ ionization limit.

In the case of one closed channel and many open channels, the cross section can be expressed as ${ }^{30,31}$

$$
\sigma(E)=\sigma_{a} \frac{(q+\varepsilon)^{2}}{1+\varepsilon^{2}}+\sigma_{b} .
$$

In this equation $\sigma_{a}$ and $\sigma_{b}$ represent two portions of the cross section which correspond, respectively, to transitions to states of the continuum that do and do not interact with the discrete autoionizing state. The reduced energy $\varepsilon$ is defined as

$$
\varepsilon=\frac{E-E_{r}}{(1 / 2) \Gamma},
$$

where $E_{r}$ is the resonance energy and $\Gamma$ is the natural width of the autoionizing state which depends on the boundcontinuum mixing of the resonance state. ${ }^{29}$

The $q$ parameter characterizes the line profile: neglecting the background cross section, the resonance has a maximum at $\varepsilon_{\max }=1 / q$ and is zero at $\varepsilon_{0}=-q$. The sign of $q$ thus determines whether the maximum occurs before or after the minimum. The magnitude of $q$ indicates qualitatively the relative probabilities of the transition to a Rydberg state and direct ionization. $^{29,30}$

If more than one closed channel exists in the region of interest and, if these channels do not interact either directly or through open channels, the photoionization cross section can be given by a superimposition of Eq. (4) over the $k$ closed channels, ${ }^{31}$ i.e.,

$$
\sigma(E)=\sum_{k} \sigma_{a k} \frac{\left(q_{k}+\varepsilon_{k}\right)^{2}}{1+\varepsilon_{k}^{2}}+\sigma_{b}
$$

If an energy region contains one open channel and many degenerate closed channels, the photoionization cross section can be written ${ }^{31}$ as

$$
\sigma(E)=\sigma_{a} \frac{\left(1+\sum_{k} q_{k} / \varepsilon_{k}\right)^{2}}{\left(1+\left(\sum_{k} q_{k} / \varepsilon_{k}\right)^{2}\right)} .
$$

In this work, codes for fitting the experimental data to Eqs. (4), (6), and (7) have been written. The parameters $\sigma_{a}, \sigma_{b}, \delta$, $q$, and $W$ in these equations are energy independent. However, a slow variation with energy of these parameters was introduced to obtain a better fit of the experimental data. ${ }^{32}$ This is achieved using a set of parameters linear in the reduced energy $X=(I-E) / R$, where $I$ is the ionization energy. The parameters (generically named $p$ ) are then written as $p$ $=p_{a}+p_{b} X$.

Several fits of the experimental spectra shown in Figs. 2(b), 3(c), and 4(b) to Eq. (6) have been performed for the case of many open and several closed channels, varying the number $k$ of the closed channels. The best results for all the three experimental spectra have been obtained, fitting the data with only two closed channels $(k=2)$. For $k=1$ it is impossible to fit the spectra where there are clearly at least
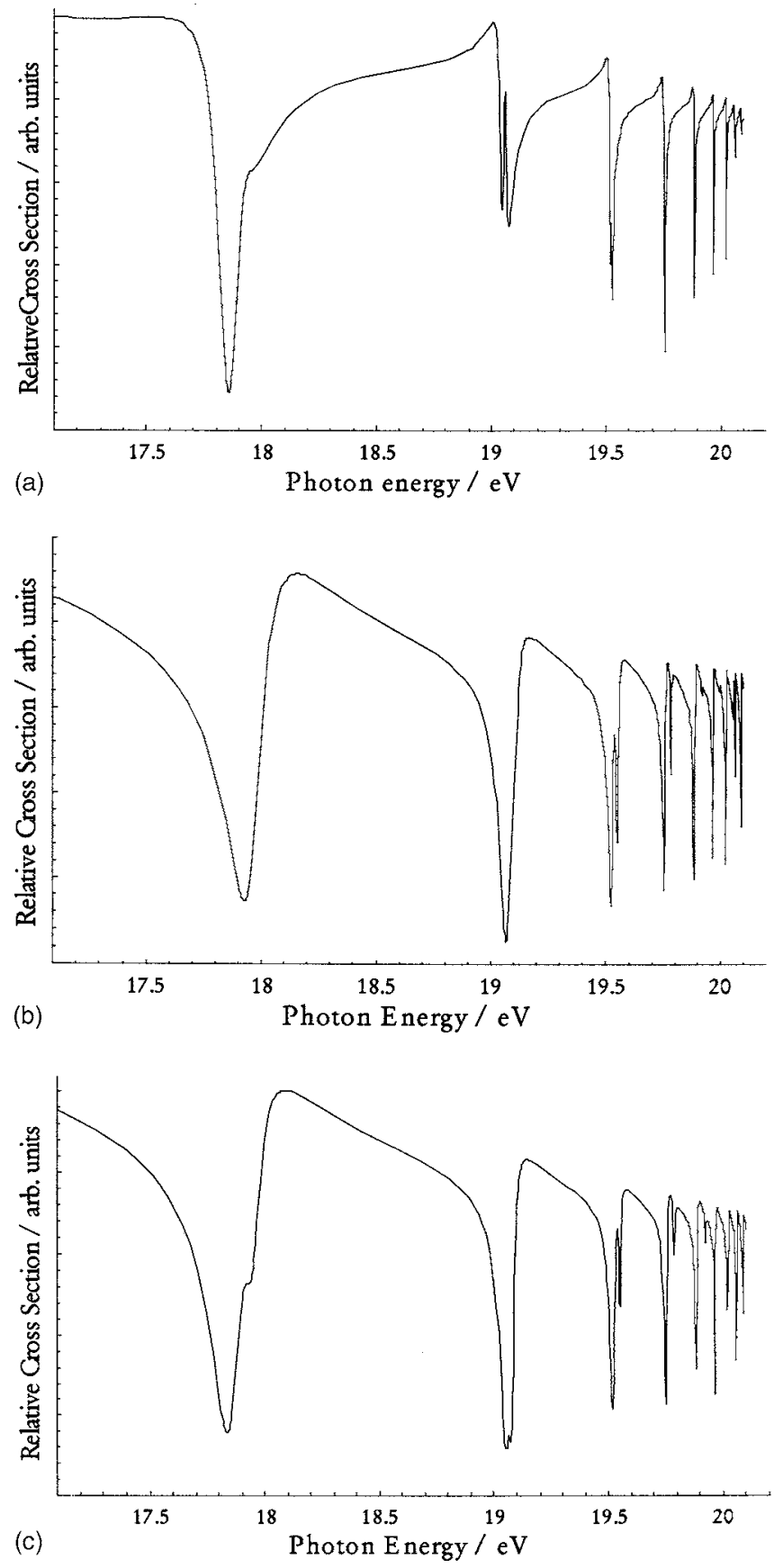

FIG. 5. (a) Fit of the data recorded for the $\mathrm{S}^{+}\left({ }^{4} S\right) \leftarrow \mathrm{S}^{*} \leftarrow \mathrm{S}\left({ }^{3} P\right)$ process in the $17.0-20.3 \mathrm{eV}$ photon energy region at $\theta=54^{\circ} 44^{\prime}$ detection angle. This should be compared with the experimental spectrum in Fig. 2(b). (b) Fit of the data recorded for the $\mathrm{S}^{+}\left({ }^{2} D\right) \leftarrow \mathrm{S}^{*} \leftarrow \mathrm{S}\left({ }^{3} P\right)$ process in the $17.5-20.3 \mathrm{eV}$ photon energy region at $\theta=54^{\circ} 44^{\prime}$ detection angle. This should be compared with the experimental spectrum in Fig. 3(c). (c) Fit of the data recorded for the $\mathrm{S}^{+}\left({ }^{2} P\right) \leftarrow \mathrm{S}^{*} \leftarrow \mathrm{S}\left({ }^{3} P\right)$ process in the $17.0-20.3 \mathrm{eV}$ photon energy region at $\theta=54^{\circ} 44^{\prime}$ detection angle. This should be compared with the experimental spectrum in Fig. 4(b).

two Rydberg series present. The fits with three Rydberg series $(k=3)$ gave the same two series obtained with $k=2$ and physically unrealistic parameter values for the third series. In Fig. 5 are shown the fits for the three CIS spectra shown in Figs. 2(b), 3(c), and 4(b). Figure 6 shows the experimental CIS spectra for the three different $(3 p)^{-1}$ ionic channels and the resonance energy positions obtained from the fits, which are also listed in Table III for each final ionic state. 

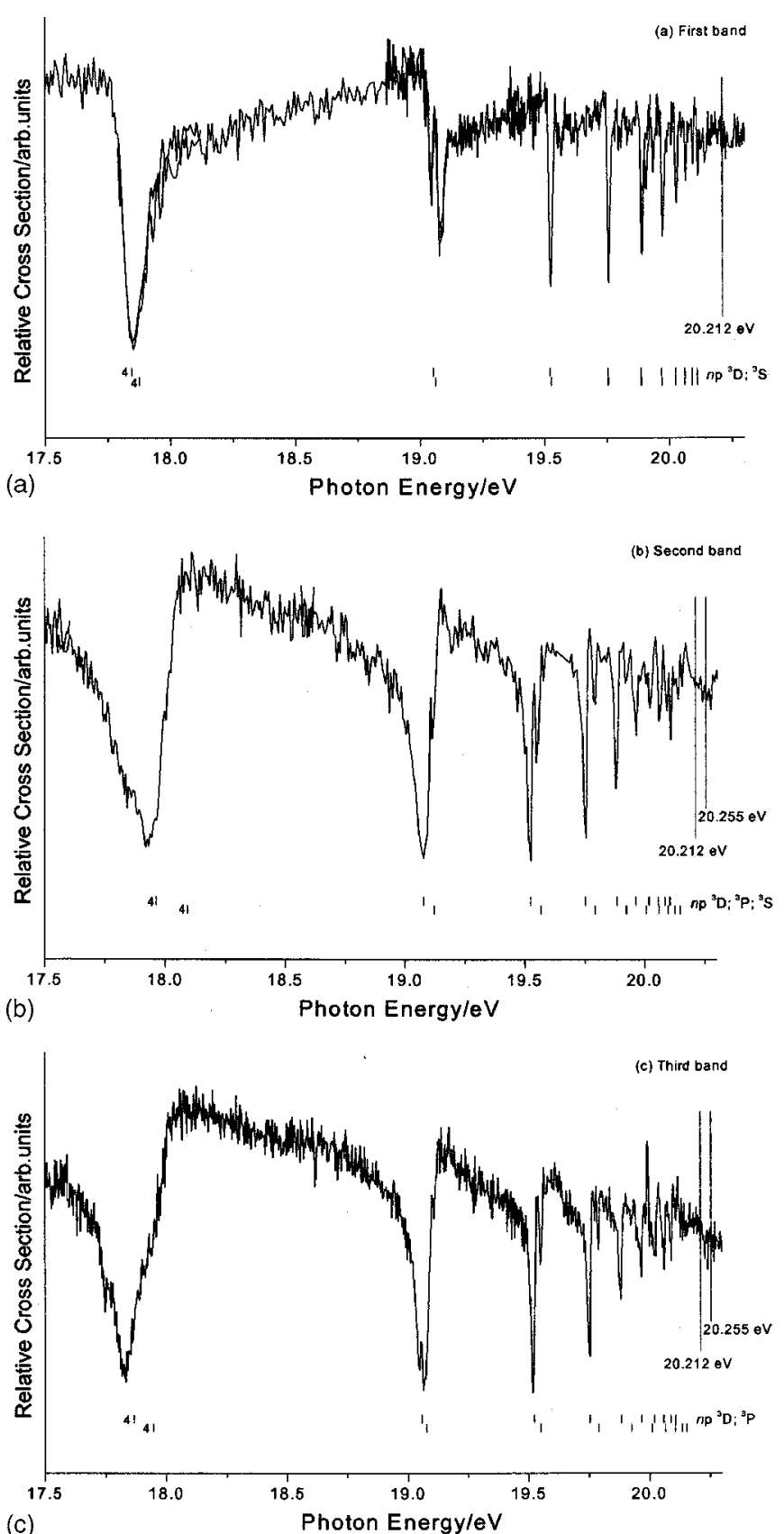

FIG. 6. CIS spectra recorded for (a) the $\mathrm{S}^{+}\left({ }^{4} S\right) \leftarrow \mathrm{S}^{*} \leftarrow \mathrm{S}\left({ }^{3} P\right)$, (b) the $\mathrm{S}^{+}\left({ }^{2} D\right) \leftarrow \mathrm{S}^{*} \leftarrow \mathrm{S}\left({ }^{3} P\right)$, and $(\mathrm{c})$ the $\mathrm{S}^{+}\left({ }^{2} P\right) \leftarrow \mathrm{S}^{*} \leftarrow \mathrm{S}\left({ }^{3} P\right)$ processes in the $17.5-20.3 \mathrm{eV}$ photon energy region, at $\theta=54^{\circ} 44^{\prime}$ detection angle, with the fourth ionization energy limits derived from analysis of the series to the ${ }^{4} P_{5 / 2}$ and ${ }^{4} P_{3 / 2}(3 s)^{-1}$ ionic states marked (see text for details). These CIS spectra are denoted as (a) first band, (b) second band, and (c) third band in the figure.

For the $\mathrm{S}^{+}\left({ }^{4} S\right) \leftarrow \mathrm{S}^{*} \leftarrow \mathrm{S}\left({ }^{3} P\right)$ process, the fit showed that there are two series converging to the same limit at $20.212 \mathrm{eV}$ while for the $\mathrm{S}^{+}\left({ }^{2} D\right) \leftarrow \mathrm{S}^{*} \leftarrow \mathrm{S}\left({ }^{3} P\right)$ and $\mathrm{S}^{+}\left({ }^{2} P\right)$ $\leftarrow \mathrm{S}^{*} \leftarrow \mathrm{S}\left({ }^{3} P\right)$ processes the fits showed that there are two series converging to two different limits at 20.212 and $20.255 \mathrm{eV}$. These two limits are, within experimental error (10 $\mathrm{meV}$ for the limits), the same as the known ionization energies from the $\mathrm{S}\left({ }^{3} P_{2}\right)$ state to the $\mathrm{S}^{+}\left({ }^{4} P_{5 / 2}\right)$ and $\mathrm{S}^{+}\left({ }^{4} P_{3 / 2}\right)$ states of 20.201 and $20.246 \mathrm{eV}$, respectively. ${ }^{12}$

According to Table II, the $\mathrm{S}^{+}\left({ }^{4} S\right) \leftarrow \mathrm{S}^{*} \leftarrow \mathrm{S}\left({ }^{3} P\right)$ CIS spectrum should have ${ }^{3} S$ and ${ }^{3} D$ Rydberg series while the
$\mathrm{S}^{+}\left({ }^{2} P\right) \leftarrow \mathrm{S}^{*} \leftarrow \mathrm{S}\left({ }^{3} P\right)$ CIS spectrum should have ${ }^{3} P$ and ${ }^{3} D$ Rydberg series. Table III shows that series 1 of the $\mathrm{S}^{+}\left({ }^{2} P\right)$ $\leftarrow \mathrm{S}^{*} \leftarrow \mathrm{S}\left({ }^{3} P\right)$ CIS spectrum has resonance energy values which are close to the values of both Rydberg series of the $\mathrm{S}^{+}\left({ }^{4} S\right) \leftarrow \mathrm{S}^{*} \leftarrow \mathrm{S}\left({ }^{3} P\right)$ CIS spectrum and has the same limit. This implies that series 1 of the $\mathrm{S}^{+}\left({ }^{2} P\right) \leftarrow \mathrm{S}^{*} \leftarrow \mathrm{S}\left({ }^{3} P\right)$ CIS spectrum should be a ${ }^{3} D$ Rydberg series but it is not sure which of series 1 and 2 of the $S^{+}\left({ }^{4} S\right) \leftarrow S^{*} \leftarrow S\left({ }^{3} P\right)$ CIS spectrum is the ${ }^{3} D$ Rydberg series; once this assignment is made the other series is a ${ }^{3} S$ Rydberg series.

Again inspection of Table II shows that the $\mathrm{S}^{+}\left({ }^{2} D\right)$ $\leftarrow \mathrm{S}^{*} \leftarrow \mathrm{S}\left({ }^{3} P\right)$ process should consist of three Rydberg series to $S^{*} D,{ }^{3} P$, and ${ }^{3} S$. Table III shows that two series are observed in the $\mathrm{S}^{+}\left({ }^{2} D\right) \leftarrow \mathrm{S}^{*} \leftarrow \mathrm{S}\left({ }^{3} P\right)$ CIS spectra, one (series 1) converging to the ground ionic state ${ }^{4} P_{5 / 2}$ and the other converging to the excited ionic state ${ }^{4} P_{3 / 2}$ (series 2). Series 1 must be a ${ }^{3} P$ Rydberg series as its energy positions are clearly different from those of $\mathrm{S}^{+}\left({ }^{4} S\right) \leftarrow \mathrm{S}^{*} \leftarrow \mathrm{S}\left({ }^{3} P\right)$ and $\mathrm{S}^{+}\left({ }^{2} P\right) \leftarrow \mathrm{S}^{*} \leftarrow \mathrm{S}\left({ }^{3} P\right)$ series which also converge to the ground ionic state (see Table III) and the ${ }^{3} S$ and ${ }^{3} D$ series converging to the ground ionic state have already been assigned.

Series 2 in the $\mathrm{S}^{+}\left({ }^{2} P\right) \leftarrow \mathrm{S}^{*} \leftarrow \mathrm{S}\left({ }^{3} P\right)$ CIS spectrum converges to the $\mathrm{S}^{+}$excited spin-orbit limit ${ }^{4} P_{3 / 2}$. Table II shows that it could be ${ }^{3} P$ and ${ }^{3} D$ Rydberg series. If it is a ${ }^{3} P$ series, its energy position for $n=4$ would be higher than the corresponding ${ }^{3} P$ resonance converging to the ${ }^{4} P_{5 / 2}$ limit [series 1 for $\left.\mathrm{S}^{+}\left({ }^{2} D\right) \leftarrow \mathrm{S}^{*} \leftarrow \mathrm{S}\left({ }^{3} P\right)\right]$, which is not the case. It is therefore possible to identify this series as a ${ }^{3} D$ Rydberg series.

Series 2 in the $\mathrm{S}^{+}\left({ }^{2} D\right) \leftarrow \mathrm{S}^{*} \leftarrow \mathrm{S}\left({ }^{3} P\right)$ CIS spectrum converges to the $\mathrm{S}^{+}{ }^{4} P_{3 / 2}$ excited state. Table II shows that it could be a ${ }^{3} S,{ }^{3} P$, or ${ }^{3} D$ Rydberg series. If it is a ${ }^{3} P$ Rydberg series, the resonance energy difference between the two $n$ $=4{ }^{3} P$ Rydberg states converging to the ${ }^{4} P_{5 / 2}$ and ${ }^{4} P_{3 / 2}$ limits is $131 \pm 36 \mathrm{meV}$ [the difference between the $n=4$ values for $\mathrm{S}^{+}\left({ }^{2} D\right) \leftarrow \mathrm{S}^{*} \leftarrow \mathrm{S}\left({ }^{3} P\right)$ series 2 and $\mathrm{S}^{+}\left({ }^{2} D\right) \leftarrow \mathrm{S}^{*} \leftarrow \mathrm{S}\left({ }^{3} P\right)$ series 1; also it should be noted that the $\mathrm{S}^{+}{ }^{4} P_{5 / 2}-{ }^{4} P_{3 / 2}$ separation is $45 \mathrm{meV} .{ }^{12}$ The difference between $131 \mathrm{meV}$ and the ionic limit difference of $45 \mathrm{meV}$ can be accounted for by small differences in the quantum defect $\delta$ for the two $n=4$ series members, i.e., $\delta=1.535$ and 1.486]. If it is a ${ }^{3} S$ or a ${ }^{3} D$ Rydberg series, the resonance energy differences between the two $n=4{ }^{3} S$ or ${ }^{3} D$ Rydberg states converging to the ${ }^{4} P_{5 / 2}$ limit are $217 \pm 36$ and $249 \pm 35 \mathrm{meV}$ [i.e., the differences in Table III between $\mathrm{S}^{+}\left({ }^{2} D\right) \leftarrow \mathrm{S}^{*} \leftarrow \mathrm{S}\left({ }^{3} P\right)$ series 2 and $\mathrm{S}^{+}\left({ }^{4} S\right)$ $\leftarrow \mathrm{S}^{*} \leftarrow \mathrm{S}\left({ }^{3} P\right)$ series 2 and 1 , respectively]. Also, for the two $\mathrm{S}^{+}\left({ }^{2} P\right) \leftarrow \mathrm{S}^{*} \leftarrow \mathrm{S}\left({ }^{3} P\right)$ series which converge to the $\mathrm{S}^{+4} P_{5 / 2}$ and ${ }^{4} P_{3 / 2}$ limits (the last two rows of Table III), the difference between the $n=4$ positions is $77 \pm 14 \mathrm{meV}$. (The difference between $77 \mathrm{meV}$ and the ionic limit difference of $45 \mathrm{meV}$ can be accounted for by small differences in the quantum defect $\delta$ for the two $n=4$ series members, i.e., $\delta$ $=1.586$ and 1.569.) Hence this evidence indicates that it is likely that series 2 of the $\mathrm{S}^{+}\left({ }^{2} D\right) \leftarrow \mathrm{S}^{*} \leftarrow \mathrm{S}\left({ }^{3} P\right)$ CIS spectrum is a ${ }^{3} P$ Rydberg series.

In this way, the only series that are not assigned are the two series in the $\mathrm{S}^{+}\left({ }^{4} S\right) \leftarrow \mathrm{S}^{*} \leftarrow \mathrm{S}\left({ }^{3} P\right)$ CIS spectrum (the first two rows of Table III). In order to obtain more information, a study of the photoelectron asymmetry parameter $\beta$ has 
TABLE III. Energy resonance positions, expressed in eV, from the fits of the CIS spectra on the three different $(3 p)^{-1}$ ionic states. Note the $\mathrm{S}^{+}\left({ }^{4} P_{5 / 2}\right) \leftarrow \mathrm{S}\left({ }^{3} P_{2}\right)$ ionization energy is $20.201 \mathrm{eV}$, the $\mathrm{S}^{+}\left({ }^{4} P_{3 / 2}\right) \leftarrow \mathrm{S}\left({ }^{3} P_{2}\right)$ ionization energy is $20.246 \mathrm{eV}$, and the $\mathrm{S}^{+}\left({ }^{4} P_{1 / 2}\right) \leftarrow \mathrm{S}\left({ }^{3} P_{2}\right)$ ionization energy is $20.271 \mathrm{eV}$ (Ref. 12).

\begin{tabular}{|c|c|c|c|c|c|}
\hline$n$ & 4 & 5 & 6 & 7 & $\infty$ \\
\hline $\begin{array}{c}\mathrm{S}^{+}\left({ }^{4} S\right) \leftarrow \mathrm{S}\left({ }^{3} P\right) \\
\text { series } 1\end{array}$ & $17.844 \pm 0.006$ & $19.053 \pm 0.002$ & $19.521 \pm 0.001$ & $19.753 \pm 0.001$ & 20.212 \\
\hline $\begin{array}{c}\mathrm{S}^{+}\left({ }^{4} S\right) \leftarrow \mathrm{S}\left({ }^{3} P\right) \\
\text { series } 2\end{array}$ & $17.876 \pm 0.011$ & $19.064 \pm 0.002$ & $19.525 \pm 0.001$ & $19.755 \pm 0.001$ & 20.212 \\
\hline $\begin{array}{c}\mathrm{S}^{+}\left({ }^{2} D\right) \leftarrow \mathrm{S}\left({ }^{3} P\right) \\
\text { series } 1\end{array}$ & $17.962 \pm 0.011$ & $19.077 \pm 0.003$ & $19.527 \pm 0.001$ & $19.753 \pm 0.001$ & 20.212 \\
\hline $\begin{array}{c}\mathrm{S}^{+}\left({ }^{2} D\right) \leftarrow \mathrm{S}\left({ }^{3} P\right) \\
\text { series } 2\end{array}$ & $18.093 \pm 0.034$ & $19.122 \pm 0.009$ & $19.566 \pm 0.004$ & $19.793 \pm 0.003$ & 20.255 \\
\hline $\begin{array}{c}\mathrm{S}^{+}\left({ }^{2} P\right) \leftarrow \mathrm{S}\left({ }^{3} P\right) \\
\text { series } 1\end{array}$ & $17.867 \pm 0.008$ & $19.058 \pm 0.002$ & $19.523 \pm 0.001$ & $19.753 \pm 0.001$ & 20.212 \\
\hline $\begin{array}{c}\mathrm{S}^{+}\left({ }^{2} P\right) \leftarrow \mathrm{S}\left({ }^{3} P\right) \\
\text { series } 2\end{array}$ & $17.944 \pm 0.011$ & $19.077 \pm 0.003$ & $19.551 \pm 0.002$ & $19.789 \pm 0.001$ & 20.255 \\
\hline
\end{tabular}

been performed for the three CIS spectra. Using CIS spectra recorded at two angles $\theta=0^{\circ}$ and $\theta=54^{\circ} 44^{\prime}$ at each photon energy, the asymmetry parameter can be calculated using Eq. (3). Comparison of the measured asymmetry parameters as a function of photon energy for the three ionization channels resulting from the $(3 p)^{-1}$ photoionization of $\mathrm{S}$ derived from this work with results of the angular distribution HartreeFock calculations of Dill et al. ${ }^{17}$ have been made over the photon energy range 10-30 eV (see Figs. 7 and 8). In Fig. 7,

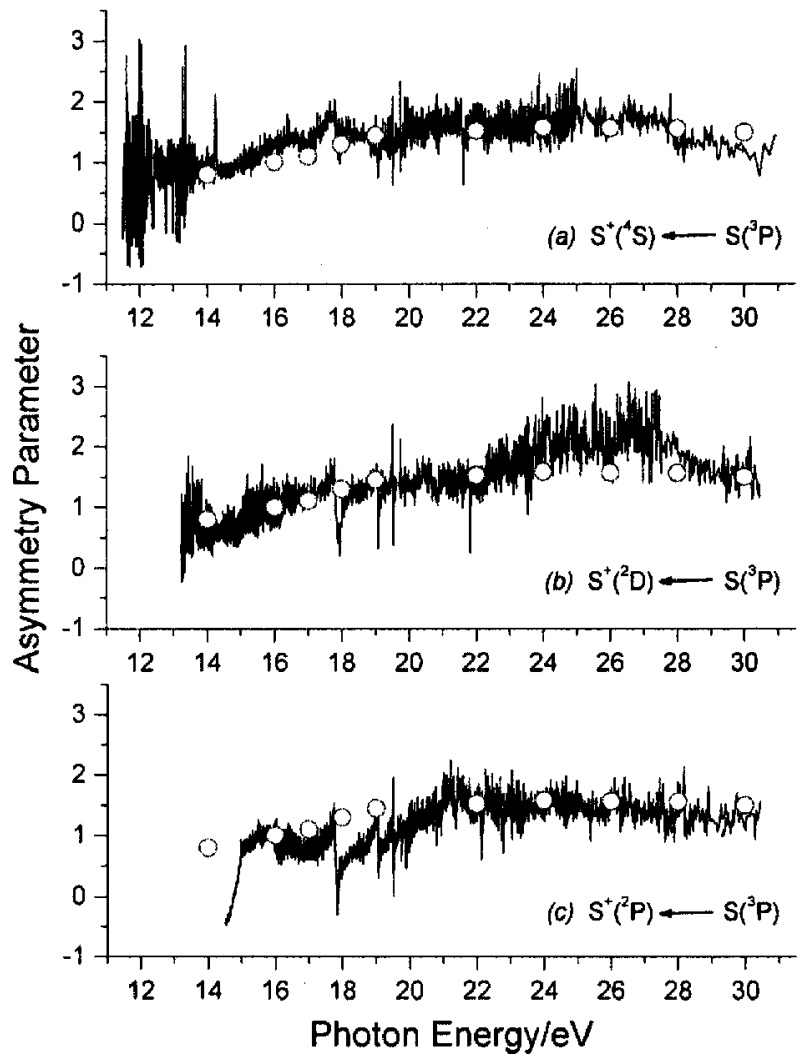

FIG. 7. Plots of the asymmetry parameter $(\beta)$ as a function of photon energy over the range $h \nu=10.0-30.0 \mathrm{eV}$ for the first three photoelectron bands of $\mathrm{S}$ atoms. All the plots include $\beta$ values for the first band of $\mathrm{H}_{2} \mathrm{~S}$ measured at different photon energies in Ref. 35, denoted with the symbol $(\bigcirc)$. This was chosen as it arises from ionization from a $\mathrm{S} 3 p$ nonbonding orbital. the three different angular distribution plots are shown as a function of photon energy and comparisons with the results of Dill et al. ${ }^{17}$ are presented in Fig. 8 . As can be seen in these figures, the experimental results obtained in this work are in reasonable agreement with the results of the calculations ${ }^{17}$ for all three ionization channels. However, the high resolution obtained with the Elettra synchrotron and the abundance of resolved resonances make a comparison difficult. Indeed, the work of Dill et al. ${ }^{17}$ was intended to provide a theoretical framework that allows angular distribution calculations to be made, at the same level as calculations of total photoionization cross sections, but does not take into account the effects of resonances. Figure 9 shows the measured asymmetry parameters as a function of photon energy over the photon energy range $16.5-20.5 \mathrm{eV}$ for the three ionization channels resulting from the $(3 p)^{-1}$ photoionization of atomic sulfur.

Fits of the experimental spectra recorded at $\theta=0^{\circ}$ as well as $54^{\circ} 44^{\prime}$ to Eq. (6) have been performed. It was then possible to evaluate the asymmetry parameter plot for the two series in each CIS spectrum from the two fitted spectra at $\theta=0^{\circ}$ and $\theta=54^{\circ} 44^{\prime}$. The asymmetry parameter plots evaluated in this way as a function of the photon energy are shown in Fig. 10. The agreement between the experimental and calculated asymmetry parameter plots is good although at higher $n$ resonances there are more "spikes" in the calculated spectra. This is principally due to a small misalignment of the resonance positions between the fitted spectra at $\theta$ $=0^{\circ}$ and $\theta=54^{\circ} 44^{\prime}$. A small misalignment of $0.5 \mathrm{meV}$ becomes important at higher $n$ where the width of the resonances is small and gives a spike effect. This effect is increased by the fact that the fits are performed without deconvoluting the data with the instrumental resolution ${ }^{33}$ and it is recognized that a fit without deconvolution of the instrumental resolution may become unreliable for an atomic transition involving narrow resonances. ${ }^{34}$ Nevertheless, this effect is expected to be small for the $n=4,5$, and 6 resonances observed in this work.

The behavior of the total asymmetry parameters as a function of photon energy in Fig. 10 cannot help the assignment of the Rydberg series. More information can, however, 

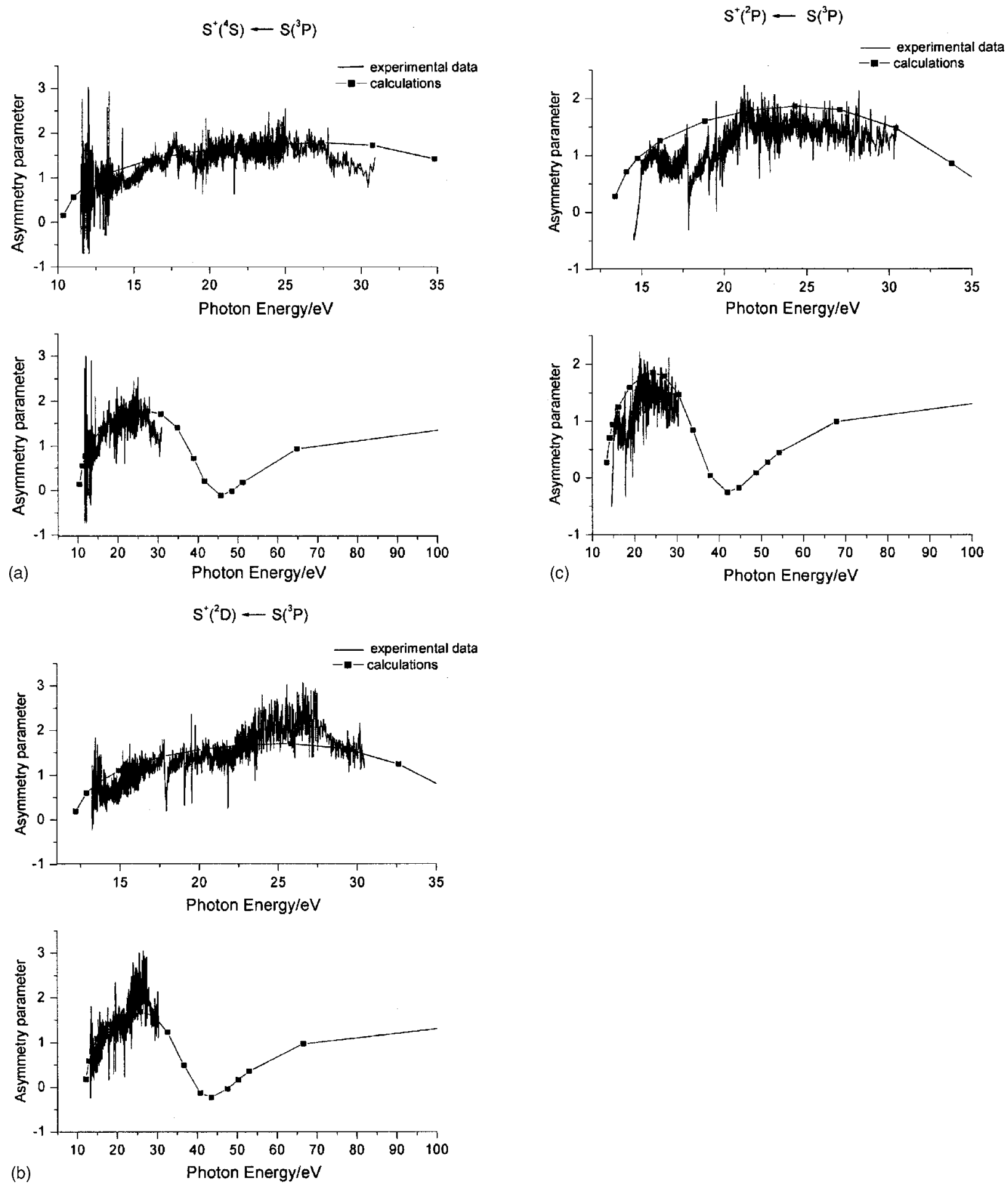

FIG. 8. (a) Asymmetry parameters for $\mathrm{S}$ atoms plotted as a function of photon energy and compared with the results of calculations of Dill et al. (Ref. 17) for the first $\mathrm{S}$ band $\mathrm{S}^{+}\left({ }^{4} \mathrm{~S}\right) \leftarrow \mathrm{S}\left({ }^{3} P\right)$. (b) Asymmetry parameters for $\mathrm{S}$ atoms plotted as a function of photon energy and compared with the results of calculations of Dill et al. (Ref. 17) for the second $\mathrm{S}$ band $\mathrm{S}^{+}\left({ }^{2} D\right) \leftarrow \mathrm{S}\left({ }^{3} P\right)$. (c) Asymmetry parameters for $\mathrm{S}$ atoms plotted as a function of photon energy and compared with the results of calculations of Dill et al. (Ref. 17) for the third $\mathrm{S}$ band $\mathrm{S}^{+}\left({ }^{2} P\right) \leftarrow \mathrm{S}\left({ }^{3} P\right)$.

be obtained from the asymmetry parameter plots of the two Rydberg series in each CIS spectrum. To determine them, the parameters of the fits at $\theta=0^{\circ}$ and $\theta=54^{\circ} 44^{\prime}$ were separated for the two series of each ionization process and the asymmetry parameter plots so obtained are shown in Figs. 11-13.

The asymmetry parameters of the two series in each of the two $\mathrm{S}^{+}\left({ }^{2} D\right) \leftarrow \mathrm{S}^{*} \leftarrow \mathrm{S}\left({ }^{3} P\right)$ and $\mathrm{S}^{+}\left({ }^{2} P\right) \leftarrow \mathrm{S}^{*} \leftarrow \mathrm{S}\left({ }^{3} P\right)$ CIS spectra have very similar behavior in the region of the resonances, as can be observed in Fig. 12 and 13. The two $\mathrm{S}^{+}\left({ }^{2} D\right) \leftarrow \mathrm{S}^{*} \leftarrow \mathrm{S}\left({ }^{3} P\right)$ series have both been assigned as ${ }^{3} P$ series and the two $\mathrm{S}^{+}\left({ }^{2} P\right) \leftarrow \mathrm{S}^{*} \leftarrow \mathrm{S}\left({ }^{3} P\right)$ series have both been assigned as ${ }^{3} D$ series. Crossing a resonance, the asymmetry parameter firstly increases its value then decreases to its value out of resonance. According to these observations 

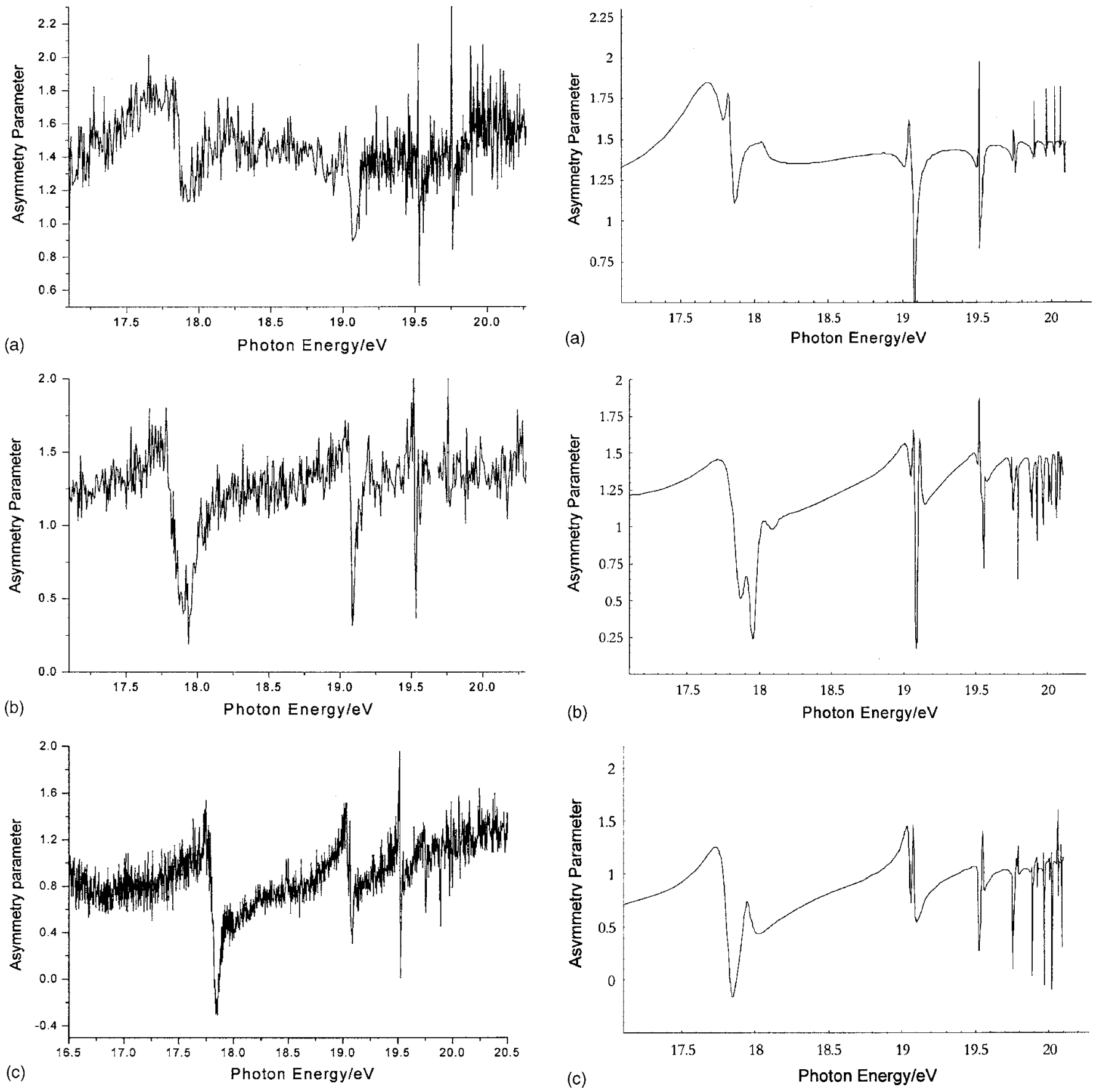

FIG. 9. (a) Spectrum of the experimental asymmetry parameter $(\beta)$ for the $\mathrm{S}^{+}\left({ }^{4} S\right) \leftarrow \mathrm{S}^{*} \leftarrow \mathrm{S}\left({ }^{3} P\right)$ ionization process as a function of the photon energy over the range $h \nu=16.5-20.5 \mathrm{eV}$. (b) Spectrum of the experimental asymmetry parameter $(\beta)$ for the $\mathrm{S}^{+}\left({ }^{2} D\right) \leftarrow \mathrm{S}^{*} \leftarrow \mathrm{S}\left({ }^{3} P\right)$ ionization process as a function of photon energy over the range $h \nu=16.5-20.5 \mathrm{eV}$. (c) Spectrum of the experimental asymmetry parameter $(\beta)$ for the $\mathrm{S}^{+}\left({ }^{2} P\right) \leftarrow \mathrm{S}^{*} \leftarrow \mathrm{S}\left({ }^{3} P\right)$ ionization process as a function of photon energy over the range $h \nu$ $=16.5-20.5 \mathrm{eV}$.

and Table II, the free electron associated with all four series has pure $d$ character; therefore similar behavior of all the four asymmetry parameter plots is expected.

The asymmetry parameter plot for Rydberg series 2 of the $\mathrm{S}^{+}\left({ }^{4} S\right) \leftarrow \mathrm{S}^{*} \leftarrow \mathrm{S}\left({ }^{3} P\right)$ CIS spectrum [Fig. 11(b)] has a behavior similar to the four series previously analyzed (Figs. 12 and 13). This means that the free electron should have a $d$ character. This property, as can be seen in Table II, is satis-

FIG. 10. (a) Spectrum of the calculated asymmetry parameter $(\beta)$ for the $\mathrm{S}^{+}\left({ }^{4} S\right) \leftarrow \mathrm{S}^{*} \leftarrow \mathrm{S}\left({ }^{3} P\right)$ ionization process as a function of photon energy over the range $h \nu=17.0-20.5 \mathrm{eV}$. This should be compared with the experimental spectrum in Fig. 9(a). (b) Spectrum of the calculated asymmetry parameter $(\beta)$ for the $\mathrm{S}^{+}\left({ }^{2} D\right) \leftarrow \mathrm{S}^{*} \leftarrow \mathrm{S}\left({ }^{3} P\right)$ ionization process as a function of photon energy over the range $h \nu=17.0-20.5 \mathrm{eV}$. This should be compared with the experimental spectrum in Fig. 9(b). (c) Spectrum of the calculated asymmetry parameter $(\beta)$ for the $\mathrm{S}^{+}\left({ }^{2} P\right) \leftarrow \mathrm{S}^{*} \leftarrow \mathrm{S}\left({ }^{3} P\right)$ ionization process as a function of photon energy over the range $h \nu=17.0-20.5 \mathrm{eV}$. This should be compared with the experimental spectrum in Fig. 9(c).

fied by the ${ }^{3} D$ Rydberg series. By elimination, the Rydberg series 1 of the $\mathrm{S}^{+}\left({ }^{4} S\right) \leftarrow \mathrm{S}^{*} \leftarrow \mathrm{S}\left({ }^{3} P\right)$ CIS spectrum is a ${ }^{3} S$ Rydberg series with a $s$ free electron. Indeed, Fig. 11(a) shows completely different behavior from Fig. 11(b) with the asymmetry parameter decreasing and then increasing while crossing a resonance. Table IV shows the six Rydberg series observed with the assignments made in this work. Inspection 

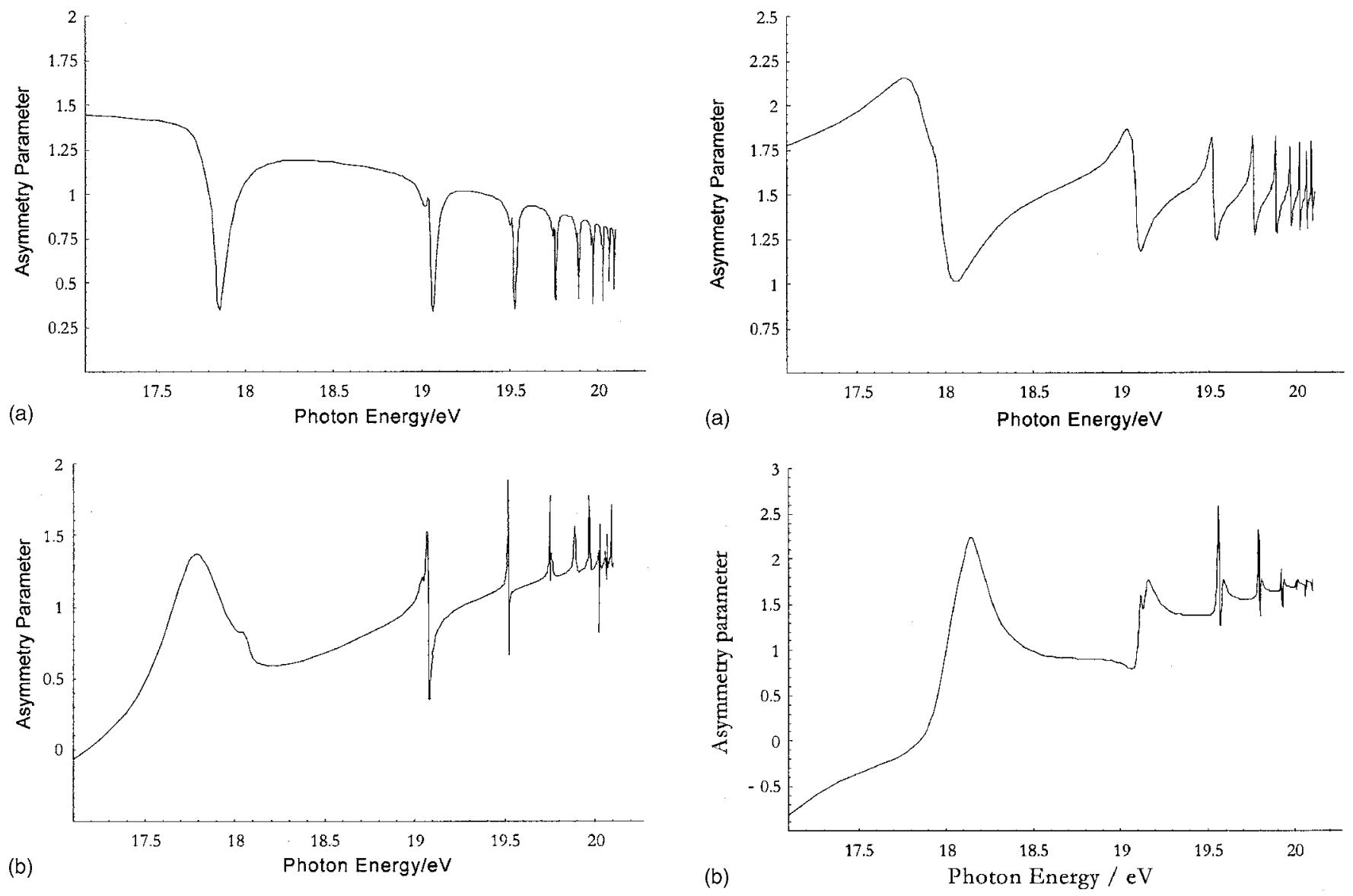

FIG. 11. (a) Spectrum of the calculated asymmetry parameter $(\beta)$ for the Rydberg series 1 of the $\mathrm{S}^{+}\left({ }^{4} S\right) \leftarrow \mathrm{S}^{*} \leftarrow \mathrm{S}\left({ }^{3} P\right)$ ionization process as a function of the photon energy over the range $h \nu=17.0-20.5 \mathrm{eV}$. (b) Spectrum of the calculated asymmetry parameter $(\beta)$ for the Rydberg series 2 of the $\mathrm{S}^{+}\left({ }^{4} \mathrm{~S}\right) \leftarrow \mathrm{S}^{*} \leftarrow \mathrm{S}\left({ }^{3} P\right)$ ionization process as a function of the photon energy over the range $h \nu=17.0-20.5 \mathrm{eV}$.

of Table III and the assignments presented in Table IV shows that $\mathrm{S}^{+}\left({ }^{4} S\right) \leftarrow \mathrm{S}^{*} \leftarrow \mathrm{S}\left({ }^{3} P\right)$ series 2 and $\mathrm{S}^{+}\left({ }^{2} P\right) \leftarrow \mathrm{S}^{*} \leftarrow \mathrm{S}\left({ }^{3} P\right)$ series 1 must be the same and, in fact, the positions of the resonances for $n=4-7$ are the same, within experimental error, for these two series. Also, the angular distribution plots should be the same for these series [Figs. 11(b) and 13(a)]. In practice, they show the same overall structure with increasing photon energy but differ in absolute values particularly in the $17.0-18.5 \mathrm{eV}$ region; this is viewed as a reflection of the experimental error associated with the procedures used.

In summary, for the first time Rydberg series converging to the fourth ionization limit have been observed for the

$$
\begin{aligned}
& \mathrm{S}^{+}\left({ }^{4} S\right) \leftarrow \mathrm{S}^{*}\left[3 s 3 p^{4}\left({ }^{4} P\right) n p\right] \leftarrow \mathrm{S}\left({ }^{3} P\right), \\
& \mathrm{S}^{+}\left({ }^{2} D\right) \leftarrow \mathrm{S}^{*}\left[3 s 3 p^{4}\left({ }^{4} P\right) n p\right] \leftarrow \mathrm{S}\left({ }^{3} P\right),
\end{aligned}
$$

and

$$
\mathrm{S}^{+}\left({ }^{2} P\right) \leftarrow \mathrm{S}^{*}\left[3 s 3 p^{4}\left({ }^{4} P\right) n p\right] \leftarrow \mathrm{S}\left({ }^{3} P\right)
$$

ionization processes. The ionic core of the excited $\mathrm{S}^{*}$ atom is split into three spin-orbit states ${ }^{4} P_{5 / 2},{ }^{4} P_{3 / 2}$, and ${ }^{4} P_{1 / 2}$. A total of five Rydberg series have been observed experimentally. Using MQDT it has been possible to fit the experimental spectra with parametrized line shape formula and to assign

FIG. 12. (a) Spectrum of the calculated asymmetry parameter $(\beta)$ for the Rydberg series 1 of the $\mathrm{S}^{+}\left({ }^{2} D\right) \leftarrow \mathrm{S}^{*} \leftarrow \mathrm{S}\left({ }^{3} P\right)$ ionization process as a function of the photon energy over the range $h \nu=17.0-20.5 \mathrm{eV}$. (b) Spectrum of the calculated asymmetry parameter $(\beta)$ for the Rydberg series 2 of the $\mathrm{S}^{+}\left({ }^{2} D\right) \leftarrow \mathrm{S}^{*} \leftarrow \mathrm{S}\left({ }^{3} P\right)$ ionization process as a function of the photon energy over the range $h \nu=17.0-20.5 \mathrm{eV}$.

the Rydberg series. ${ }^{3} S,{ }^{3} P$, and ${ }^{3} D$ Rydberg series converging to the ${ }^{4} P_{5 / 2}$ limit have been identified as well as ${ }^{3} P$ and ${ }^{3} D$ Rydberg series converging to the higher ${ }^{4} P_{3 / 2}$ limit.

Nine possible series were expected. For the $\mathrm{S}^{+}\left({ }^{2} D\right)$ $\leftarrow S^{*} \leftarrow S\left({ }^{3} P\right)$ CIS spectrum, two of them were observed and these converge to the $\mathrm{S}^{+}\left({ }^{4} P_{5 / 2}\right)$ and $\mathrm{S}^{+}\left({ }^{4} P_{3 / 2}\right)$ limits. These series correspond to ${ }^{3} P$ excited states.

For the $\mathrm{S}^{+}\left({ }^{4} S\right) \leftarrow \mathrm{S}^{*} \leftarrow \mathrm{S}\left({ }^{3} P\right)$ CIS spectrum only six of the possible nine series are allowed on the basis of selection rules. Two of the possible six series were observed and these two series both converge to the $\mathrm{S}^{+}\left({ }^{4} P_{5 / 2}\right)$ limit. Series 1 (the series with lower resonance energies for a given $n$ ) arises from ${ }^{3} S$ excited states whereas series 2 corresponds to ${ }^{3} D$ excited states.

For the $\mathrm{S}^{+}\left({ }^{2} P\right) \leftarrow \mathrm{S}^{*} \leftarrow \mathrm{S}\left({ }^{3} P\right)$ CIS spectrum again only six of the nine series are allowed on the basis of selection rules. Two of the six possible series were observed and these converge to the $\mathrm{S}^{+}\left({ }^{4} P_{5 / 2}\right)$ and $\mathrm{S}^{+}\left({ }^{4} P_{3 / 2}\right)$ limits. Both the series correspond to ${ }^{3} D$ excited states.

The reason why only some of the expected excited states are observed in these CIS experiments must be due to their relative cross section for their production from the ground state as well as their efficiency of autoionization to the selected ionic state, which favors their observation over the other "dark" states. 

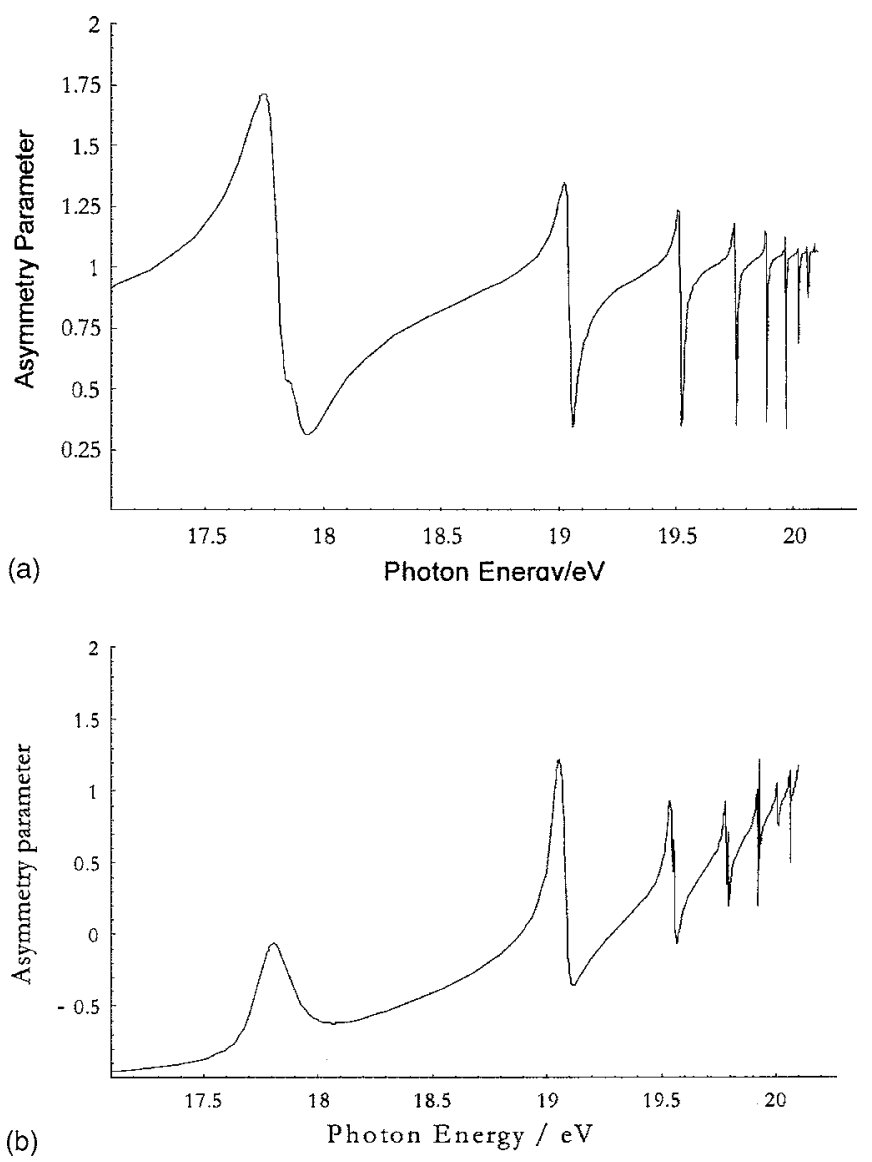

FIG. 13. (a) Spectrum of the calculated asymmetry parameter $(\beta)$ for the Rydberg series 1 of the $\mathrm{S}^{+}\left({ }^{2} P\right) \leftarrow \mathrm{S}^{*} \leftarrow \mathrm{S}\left({ }^{3} P\right)$ ionization process as a function of the photon energy over the range $h \nu=17.0-20.5 \mathrm{eV}$. (b) Spectrum of the calculated asymmetry parameter $(\beta)$ for the Rydberg series 2 of the $\mathrm{S}^{+}\left({ }^{2} P\right) \leftarrow \mathrm{S}^{*} \leftarrow \mathrm{S}\left({ }^{3} P\right)$ ionization process as a function of the photon energy over the range $h \nu=17.0-20.5 \mathrm{eV}$.

\section{CONCLUSIONS}

In this work, the angular distribution parameters and relative photoionization cross sections for the $\mathrm{S}^{+}\left({ }^{4} S\right)$ $\leftarrow \mathrm{S}\left({ }^{3} P\right), \mathrm{S}^{+}\left({ }^{2} D\right) \leftarrow \mathrm{S}\left({ }^{3} P\right)$, and $\mathrm{S}^{+}\left({ }^{2} P\right) \leftarrow \mathrm{S}\left({ }^{3} P\right)(3 p)^{-1}$ ionizations have been determined as a function of photon energy from threshold to $31 \mathrm{eV}$, with CIS spectroscopy. All spectra were recorded at two angles, $\theta=0^{\circ}$ and $\theta=54^{\circ} 44^{\prime}$, with respect to the polarization axis of the photon source. CIS spectra were successfully recorded for the $\mathrm{S}^{+}\left({ }^{4} S\right) \leftarrow \mathrm{S}\left({ }^{3} P\right)$ ionization at $10.35 \mathrm{eV}$, for the $\mathrm{S}^{+}\left({ }^{2} D\right) \leftarrow \mathrm{S}\left({ }^{3} P\right)$ ionization at $12.20 \mathrm{eV}$, and for the $\mathrm{S}^{+}\left({ }^{2} P\right) \leftarrow \mathrm{S}\left({ }^{3} P\right)$ ionization at $13.40 \mathrm{eV}$.

TABLE IV. Summary of the assignments made for the six Rydberg series observed.

\begin{tabular}{llcc}
\hline \hline Final CIS ionic state & $\begin{array}{l}\text { Ionic } \\
\text { limit }\end{array}$ & Excited state & $\begin{array}{c}\text { Free } \\
\text { electron }\end{array}$ \\
\hline$\left(3 s^{2} 3 p^{3}\right) \mathrm{S}^{+}\left({ }^{4} S\right)$ series 1 & ${ }^{4} P_{5 / 2}$ & {$\left[3 s 3 p^{4}\left({ }^{4} P\right) n p\right]{ }^{3} S$} & $\varepsilon s$ \\
$\left(3 s^{2} 3 p^{3}\right) \mathrm{S}^{+}\left({ }^{4} S\right)$ series 2 & ${ }^{4} P_{5 / 2}$ & {$\left[3 s 3 p^{4}\left({ }^{4} P\right) n p\right]{ }^{3} D$} & $\varepsilon d$ \\
$\left(3 s^{2} 3 p^{3}\right) \mathrm{S}^{+}\left({ }^{2} D\right)$ series 1 & ${ }^{4} P_{5 / 2}$ & {$\left[3 s 3 p^{4}\left({ }^{4} P\right) n p\right]{ }^{3} P$} & $\varepsilon d$ \\
$\left(3 s^{2} 3 p^{3}\right) \mathrm{S}^{+}\left({ }^{2} D\right)$ series 2 & ${ }^{4} P_{3 / 2}$ & {$\left[3 s 3 p^{4}\left({ }^{4} P\right) n p\right]{ }^{3} P$} & $\varepsilon d$ \\
$\left(3 s^{2} 3 p^{3}\right) \mathrm{S}^{+}\left({ }^{2} P\right)$ series 1 & ${ }^{4} P_{5 / 2}$ & {$\left[3 s 3 p^{4}\left({ }^{4} P\right) n p\right]{ }^{3} D$} & $\varepsilon d$ \\
$\left(3 s^{2} 3 p^{3}\right) \mathrm{S}^{+}\left({ }^{2} P\right)$ series 2 & ${ }^{4} P_{3 / 2}$ & {$\left[3 s 3 p^{4}\left({ }^{4} P\right) n p\right]{ }^{3} D$} & $\varepsilon d$ \\
\hline \hline
\end{tabular}

This study has highlighted the presence of several structures that were not observed in the earlier PE investigation. ${ }^{1}$ Inspection of the CIS spectra has shown that all the bands converging to the second and third ionization limits can be assigned to excitation to known Rydberg states.

Also, for the first time Rydberg series converging to the fourth ionization limit have been observed and assignments have been proposed. These correspond to excitations to Rydberg states that are parts of series which converge to the fourth ionization limit, $\mathrm{S}^{+}\left({ }^{4} P\right) \leftarrow \mathrm{S}\left({ }^{3} P\right)(3 s)^{-1}$, and autoionize to the lower $\mathrm{S}^{+}\left({ }^{4} S\right), \mathrm{S}^{+}\left({ }^{2} D\right)$, or $\mathrm{S}^{+}\left({ }^{2} P\right)$ states. In each case, the excited state symmetry and the principal quantum number of the Rydberg orbital in the excited state are determined by consideration of the selection rules for excitation from the ground $\mathrm{S}\left({ }^{3} P\right)$ state and determination of the band positions from analysis of the profile of the resonances, as well as results of angular resolved CIS measurements. For each series, the angular momentum character of the free electron on autoionization has been determined from these angular distribution studies. Of the expected nine series, only five were observed.

\section{ACKNOWLEDGMENTS}

The authors are grateful to EPSRC for support. They also thank Dr. N. Zema and Dr. S. Turchini and the technical staff on the Polar beamline (4.2R) at Elettra, Trieste for help and advice.

${ }^{1}$ L. Zuin, F. Innocenti, M. L. Costa, A. A. Dias, A. Morris, A. C. S. Paiva, S. Stranges, J. B. West, and J. M. Dyke, Chem. Phys. 298, 213 (2004).

${ }^{2}$ L. Beeching, A. A. Dias, J. M. Dyke, A. Morris, S. Stranges, J. B. West, N. Zema, and L. Zuin, Mol. Phys. 101, 575 (2003).

${ }^{3}$ F. Innocenti, L. Zuin, M. L. Costa, A. A. Dias, A. Morris, A. C. S. Paiva, S. Stranges, J. B. West, and J. M. Dyke, J. Electron Spectrosc. Relat. Phenom. 142, 241 (2005).

${ }^{4}$ J. D. Barr, A. de Fanis, J. M. Dyke, S. D. Gamblin, A. Morris, S. Stranges, J. B. West, and T. G. Wright, J. Chem. Phys. 109, 2737 (1998). ${ }^{5}$ F. Innocenti, M. L. Costa, A. A. Dias, M. Goubet, A. Morris, R. I. Oleriu, S. Stranges, N. Zema, and J. M. Dyke, Mol. Phys. (to be published).

${ }^{6}$ F. Innocenti, L. Zuin, M. L. Costa, A. A. Dias, M. Goubet, A. Morris, R. I. Oleriu, S. Stranges, and J. M. Dyke, Mol. Phys. (to be published).

${ }^{7}$ Z. Altun, J. Phys. B 25, 2279 (1992).

${ }^{8}$ K. Sinha, Proc. Astron. Soc. Aust. 9, 32 (1991).

${ }^{9}$ R. P. Wayne, J. Photochem. Photobiol., A 62, 379 (1992).

${ }^{10}$ G. G. Lombardi, B. L. Cardon, and R. L. Kurucz, Astrophys. J. 248, 1208 (1981); J. E. Vernazza, E. H. Averett, and R. Loeser, Astrophys. J., Suppl. Ser. 45, 635 (1981).

${ }^{11}$ M. L. Meeks, M. A. Gordon, and M. M. Litvak, Science 163, 173 (1969).

${ }^{12}$ C. E. Moore, Atomic Energy Levels, Nat. Bur. Stand. (U.S.) Cine. No. 467 (U.S. GPO, Washington, DC, 1949), Vol. 1.

${ }^{13}$ S. T. Gibson, J. P. Green, B. Ruscic, and J. Berkowitz, J. Phys. B 19, 2825 (1986).

${ }^{14}$ G. Tondello, Astrophys. J. 172, 771 (1972).

${ }^{15}$ S. Woutersen, J. B. Milan, W. J. Buma, and C. A. de Lange, Phys. Rev. A 54, 5126 (1996).

${ }^{16}$ S. Woutersen, J. B. Milan, W. J. Buma, and C. A. de Lange, J. Chem. Phys. 106, 6831 (1997).

${ }^{17}$ D. Dill, A. F. Starace, and S. T. Manson, Phys. Rev. A 11, 1596 (1975).

${ }^{18}$ M. C. R. Cockett, J. M. Dyke, and H. Zamanpour, Vacuum Ultraviolet Photoionization and Photodissociation of Molecules and Clusters, edited by C. Y. Ng (World Scientific, Singapore, 1991).

${ }^{19}$ A. Derossi, F. Lama, M. Piacentini, T. Prosperi, and N. Zema, Rev. Sci. Instrum. 66, 1718 (1995).

${ }^{20}$ D. Desiderio, S. DiFonzo, B. Diviacco et al., Synchrotron Radiat. News 12, 34 (1999). 
${ }^{21}$ W. F. Chan, G. Cooper, X. Guo, G. R. Burton, and C. E. Brion, Phys. Rev. A 46, 149 (1992).

${ }^{22}$ http://physics.nist.gov/PhysRefData

${ }^{23}$ S. J. Dunlavey, J. M. Dyke, N. K. Fayad, N. Jonathan, and A. Morris, Mol. Phys. 38, 729 (1979).

${ }^{24}$ K. Kimura, S. Katsumata, Y. Achiba, T. Yamazaki, and S. Iwata, Handbook of HeI Photoelectron Spectra of Fundamental Organic Molecules (Japan Scientific Societies Press, Tokyo, 1981).

${ }^{25}$ D. Muller, Z. Naturforsch. A 23A, 1707 (1968).

${ }^{26}$ J. J. Yeh and I. Lindau, At. Data Nucl. Data Tables 32, 1 (1985).

${ }^{27}$ Y. N. Joshi, M. Mazzoni, A. Nencioni, W. H. Parkinson, and A. Cantu, J.
Phys. B 20, 1203 (1987).

${ }^{28}$ H. G. Kuhn, Atomic Spectra (Longmans, London, 1964).

${ }^{29}$ U. Fano, Phys. Rev. 124, 1866 (1961).

${ }^{30}$ U. Fano and J. W. Cooper, Phys. Rev. 137, 1364 (1965).

${ }^{31}$ K. Ueda, Phys. Rev. A 35, 2484 (1987).

${ }^{32}$ J. Dubau and M. J. Seaton, J. Phys. B 17, 381 (1984).

${ }^{33}$ K. Maeda, K. Ueda, and K. Ito, J. Phys. B 26, 1541 (1993).

${ }^{34}$ T. K. Fang and T. N. Chang, Phys. Rev. A 57, 4407 (1998).

${ }^{35}$ P. Baltzer, L. Karlsson, M. Ludqvist, B. Wannberg, D. M. P. Holland, and M. A. MacDonald, Chem. Phys. 195, 403 (1995). 